\title{
Molecular Imprints Frozen by Strong Intermolecular Interactions in Place of Cross-linking
}

\author{
Cherifa Ayadi, ${ }^{[a, b, c]}$ Amira Anene, ${ }^{[a]}$ Rafik Kalfat, ${ }^{[a]}$ Yves Chevalier, ${ }^{*[b]}$ Souhaira Hbaieb ${ }^{*}[a, c]$
}

[a] C. Ayadi, A. Anene, R. Kalfat, S. Hbaieb

Laboratoire Méthodes et Techniques d'Analyse

Institut National de Recherche et d'Analyse Physico-chimique (INRAP)

Biotechpole Sidi-Thabet, 2020 Ariana, Tunisia

E-mail: souhaira.hbaieb@fst.utm.tn

[b] C. Ayadi, Y. Chevalier

Laboratoire d'Automatique, de Génie des Procédés et de Génie Pharmaceutique (LAGEPP)

Université de Lyon 1, UMR 5007 CNRS

43 bd 11 Novembre, 69622 Villeurbanne, France

E-mail: yves.chevalier@univ-lyon1.fr

[c] C. Ayadi, S. Hbaieb

Faculté des Sciences de Tunis

Université Tunis El Manar

Campus Universitaire El Manar, Tunisia

E-mail:

Supporting information for this article is given via a link at the end of the document

\begin{abstract}
A new way to freeze molecular imprints in a polymer material is reported. So far, molecular imprinted polymers (MIP) involve copolymerization of a functional monomer and large amounts of cross-linking agent that keeps the template shape memory in rigid molecular imprints. MIP materials are presently prepared without cross-linking agent. Stiff chains of polyaniline grafted on a solid support as a brush-like material achieve the necessary rigidity. Differential adsorption to imprinted and non-imprinted materials provides evidence of molecular imprints. A correct adsorption isotherm for mobile adsorbed layers (Volmer isotherm) is introduced instead of the popular but inadequate Langmuir isotherm. Nonselective adsorption is entropic, whereas adsorption to molecular imprints has an enthalpic contribution coming from specific interactions. Fast adsorption kinetics is a definite benefit with regards to applications such as chromatographic separations and chemical sensors.
\end{abstract}

\section{Introduction}

Molecularly Imprinted Polymers (MIP's) ${ }^{[1,2]}$ are strongly crosslinked polymer materials where selective binding sites have been created by running polymerization in the presence of the target molecule. According to the original concept introduced by Wulff, ${ }^{[3,4]}$ the target molecule is a template for polymerization; removal of the latter leaves a "cavity" having the size and shape of the target molecule, creating a site for its selective adsorption. The classical design of MIP's uses a functional monomer associated with a high amount of cross-linker $(\sim 50 \%)$, so that polymerization freezes motions at a molecular scale. Various applications are in areas where selective adsorption definitely matters: analytical chemistry, ${ }^{[1,5,6]}$ catalysis, ${ }^{[7]}$ chemical sensors, ${ }^{\left[{ }^{[8]}\right.}$ biochemical processes, ${ }^{\left[{ }^{9]}\right.}$... The requirements for such materials are (i) strong rigidity of the polymer material brought about by tight cross-linking and (ii) high density and accessibility of binding sites coming from large specific area and controlled porosity.
MIP's are often stated as mimicking nature because the selective molecular recognition relies on host-guest interactions based on molecular shape. It is claimed that selective adsorption looks like that to enzymes. ${ }^{[10-12]}$ In this latter case, a low crosslinking density by disulfide bridges holds the secondary and tertiary structures of enzymes, the shape of molecular recognition sites being set by hydrogen bonding, hydrophobic and electrostatic interactions. So, a high density of cross-linking is not mandatory for keeping molecular imprints.

A new way for freezing host-guest interactions is presently introduced by combining the effects of polymer chain stiffness and binding a thin polymer film to a solid surface. Chemical crosslinking is replaced by strong lateral interactions between stiff macromolecules leading to their quasi-crystallization inside a thin polymer film. Polymer materials known as undergoing easy crystallization are made of rigid linear macromolecules, especially polyconjugated (conductive) ones; poly(aniline) (PANI) was presently selected.

Using a thin MIP film at the surface of a solid material is a suitable alternative to the classical design of MIP's as polymer beads where selective binding capacity and accessibility to adsorption sites is ensured by addition of a "porogen" (nonsolvent of the polymer or sacrificial solid particles) that generates porosity. ${ }^{[13-15]}$ Simultaneous control of accessibility and capacity relies on a compromise as high accessibility calls for large pore size that is detrimental to specific area. An alternative consists in coating a porous solid material with a thin film of MIP, so the two requirements for accessibility through controlled porosity and small cavities for molecular recognition are decoupled and easier to manage. We recently reported ${ }^{[16,17]}$ MIP's of Patulin toxin based on thin coatings on silica that exhibited higher adsorption capacity and faster adsorption dynamics. The MIP was prepared by copolymerization with monomers chemically bound to the surface for ensuring strong binding of the MIP coating. The thickness of active coating of the order of few sizes of guest molecule (1 or 2 nanometers) should be enough for imprints can be formed. In a 
thicker layer, part of the molecular imprints would be buried inside the coating. Such inactive part might impair the performance because buried template molecules are difficult to remove by solvent extraction and they might slowly leak off, resulting in drift of characteristics and poor overall stability of the performances. Thin films of MIP materials have already been implemented for the application to chemical sensors by casting cross-linked MIP onto the surface of the transducer, because a high capacity of adsorption is not a requirement. ${ }^{[18-22]}$

The water-soluble sunscreen benzophenone-4 (BP4, 4hydroxy-2-methoxy-5-(oxo-phenylmethyl)benzenesulfonic acid, CAS 4065-45-6) was taken as guest molecule because its harmful properties in the environment ${ }^{[23-25]}$ makes its detection and analysis in aquatic media a definite concern. This polyaromatic sulfonic acid acts as a dopant for PANI; its anion might show strong interactions with PANI, especially with its cationic emeraldine salt form. In general, PANI has the ability of interacting with many analytes through hydrogen bonding, $\pi-\pi$ stacking ${ }^{[26]}$ and electrostatic interactions when doped in acidic medium.

The PANI MIP was prepared as a thin film starting from a porous silica support grafted with aniline $\left(\mathrm{ANI} @ \mathrm{SiO}_{2}\right)$ as outlined in Figure 1. The classical oxidative polycondensation of aniline monomer in acidic medium yielded conductive PANI under its emeraldine salt form. At variance with previously reported materials based on PANI, ${ }^{[27,28]}$ a very thin PANI layer strongly attached to silica was preferred. Since polymerization of aniline yields crystalline PANI particles that do not bind to silica, ${ }^{[29]}$ PANI binding was ensured by grafting silica with an organosilane containing the aniline moiety that could copolymerize with aniline.

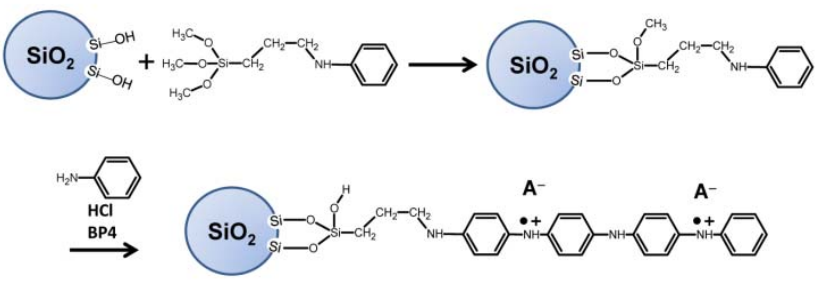

Figure 1. Two steps synthesis scheme of molecularly imprinted PANI in emeraldine salt form. The first step is grafting of aniline to silica surface by means of silane chemistry; the second step is copolymerization of free and grafted aniline in $\mathrm{HCl}$ medium in the presence of the $\mathrm{BP} 4$ sulfonic acid. $\mathrm{A}^{-}$stands for either $\mathrm{Cl}^{-}$or $\mathrm{BP}^{-}$coming from doping acids.

As summary, the present paper reports a proof of concept for crosslinker-free MIP's based on strong intermolecular interactions within the polymer material. Such interactions are the same as those responsible for the easy crystallization of PANI. Copolymerization of free and grafted aniline at the surface in the

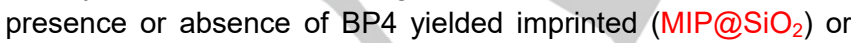
non-imprinted (NIP@SiO ${ }_{2}$ ) coatings, respectively. The adsorption mechanisms of MIP toward BP4 molecules were assessed by studying the thermodynamics of adsorption equilibrium. Adsorption kinetics was assessed as it is of high relevance regarding performance of analytical devices. The purpose of this paper is to make a proof of concept better than reaching high performance of a material to be used in analysis devices. For that reason, selectivity with respect to interfering molecules was not addressed.

\section{Results and Discussion}

\section{Preparation and optimization of MIP@SiO 2 material}

The strategy for the preparation of BP4-imprinted polyaniline $\left(\mathrm{MIP} @ \mathrm{SiO}_{2}\right) \quad$ (Figure 1) combines the surface imprinting technique and the use of the rigid PANI polymer as a matrix for cross-linking becomes optional. APTMS containing aniline group was firstly grafted onto silica, providing $\mathrm{ANI} @ \mathrm{SiO}_{2}$ with covalently attached aniline monomers available for subsequent copolymerization.

Covalent grafting of APTMS to silica surface by means of a hydrolysis-condensation reaction is a well-known process ${ }^{[30,31]}$ reported in section SI2 of Supporting Information together with the characterization of $\mathrm{ANI@SiO}$. The grafting density was $2.24 \mu \mathrm{mol} \cdot \mathrm{m}^{-2}$ (conditions $\mathrm{ANI} 1 @ \mathrm{SiO}_{2}$ in Table S1), which corresponds to coverage by a monolayer of grafted silane.

The MIP material BP4-MIP@SiO ${ }_{2}$ was prepared by oxidative copolymerization of aniline groups of $\mathrm{ANI} @ \mathrm{SiO}_{2}$ and aniline monomer added in the acidic reaction medium containing the template molecule BP4. The polymerization of aniline is usually performed in strongly acidic medium $(\mathrm{HCl}$ concentration in the range $0.1-1 \mathrm{M}$ ) for generating the conductive emeraldine salt form. The anionic BP4 should strongly interact with PANI chains for the dopant is the BP4 sulfonic acid. Chloride anions of $\mathrm{HCl}$ are competitive binders with $\mathrm{BP} 4$, so that the concentration of $\mathrm{HCl}$ has been reduced to minimum required for the formation of the emeraldine salt form of PANI. Polymerization of aniline was achieved at $\mathrm{pH} 4$ where aniline is still predominantly protonated under anilinium form (80\% according to its pKa of 4.60$)$ and the produced PANI is under its emeraldine salt form ( $p K a$ of PANI is $4.86^{[32]}$ ). This weakly acidic medium is also favorable as hydrolysis side-reactions are minimized in the $\mathrm{pH}$ range $2-4{ }^{[33]} \mathrm{A}$ grafted PANI layer incorporating BP4 was formed at the surface of the solid silica support. A large excess of aniline with respect to expected thickness was used. The main part of PANI strands were not attached to the silica surface by copolymerization. It was washed off during subsequent filtration. The thickness of the PANI coating is mainly determined by the copolymerization kinetics.

There is an optimum density of binding sites because of two contradictory phenomena. A high density of interaction sites would provide a high capacity for binding BP4. But a too high density of sites disturbs the materials structure and impairs selectivity of binding. The monomer/template (aniline/BP4) ratio was adjusted by a series of experiments. The adsorption performance revealed by BP4 uptake to washed materials (Figure 2) shows that a monomer/template mole ratio of five yielded the highest BP4 uptake and the largest difference between MIP and NIP. This ratio was suitable for high imprinting density and selectivity. The large difference of adsorbed BP4 between MIP and NIP materials definitely shows that molecular imprints have been retained after extraction of the template though no chemical cross-linking has been implemented.

Extraction of BP4 from BP4-MIP@ $\mathrm{SiO}_{2}$ yielding the final $\mathrm{MIP@SiO_{2 }}$ was performed in a basic medium $(0.3 \mathrm{M}$ aqueous ammonia) that suppressed electrostatic interactions between cationic groups of PANI and anionic BP4. Extraction with a basic medium greatly improved the kinetics of BP4 removal from the molecular imprints. Though it converted PANI into its softer emeraldine base form, the loss of rigidity during extraction did not 
cause a loss of shape memory of molecular imprints. Similar extraction process for MIP preparation relying on softening the material using thermally reversible cleavage of urethane bonds has already been reported with no loss of selectivity. ${ }^{[34]}$

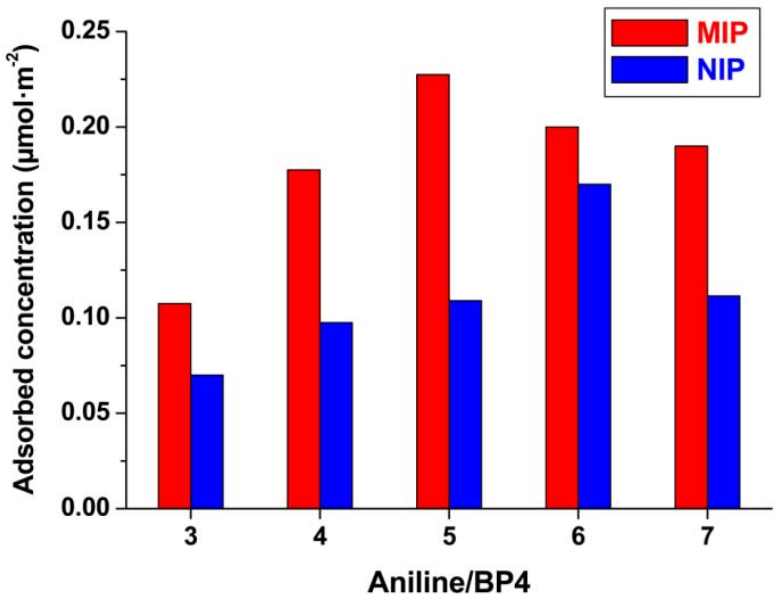

Figure 2. Influence of the aniline to BP4 ratio on adsorbed BP4 concentration upon exposure of $2 \mathrm{~g} \cdot \mathrm{L}^{-1} \mathrm{MIP} @ \mathrm{SiO}_{2}$ or NIP@SiO 2 to a $60 \mu \mathrm{mol} \cdot \mathrm{L}^{-1}$ solution of $\mathrm{BP} 4$ at $\mathrm{pH} 4$

\section{Characterization of ${\mathrm{MIP} @ \mathrm{SiO}_{2}}_{2}$ NIP@SiO 2 materials}

IR spectra of NIP@SiO, MIP@SiO $\mathrm{SiO}_{2}$ and BP4-MIP@SiO (Figure 3) showed absorption bands located at $1598 \mathrm{~cm}^{-1}$ and $1497 \mathrm{~cm}^{-1}$ associated to $\mathrm{C}=\mathrm{C}$ stretching vibrations of quinonoid and benzenoid rings of PANI, respectively. Equal intensities of these two peaks confirmed the formation of the emeraldine form of PANI. The band at $1298 \mathrm{~cm}^{-1}$ corresponding to the C-N stretching mode cannot be observed as it is superimposed to the strong Si-O-Si stretching vibration of silica. The IR spectrum of

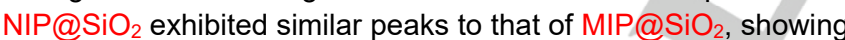
that BP4 has successfully been removed from the polymer matrix. Supplementary peaks at $1600 \mathrm{~cm}^{-1}, 1260 \mathrm{~cm}^{-1}$ and $609 \mathrm{~cm}^{-1}$ corresponding to the $\mathrm{C}=\mathrm{O}$ stretching mode, $\mathrm{S}=\mathrm{O}$ and $\mathrm{C}-\mathrm{S}$ stretching vibrations of BP4 respectively were observed before extraction of BP4 (BP4-MIP@SiO ${ }_{2}$.

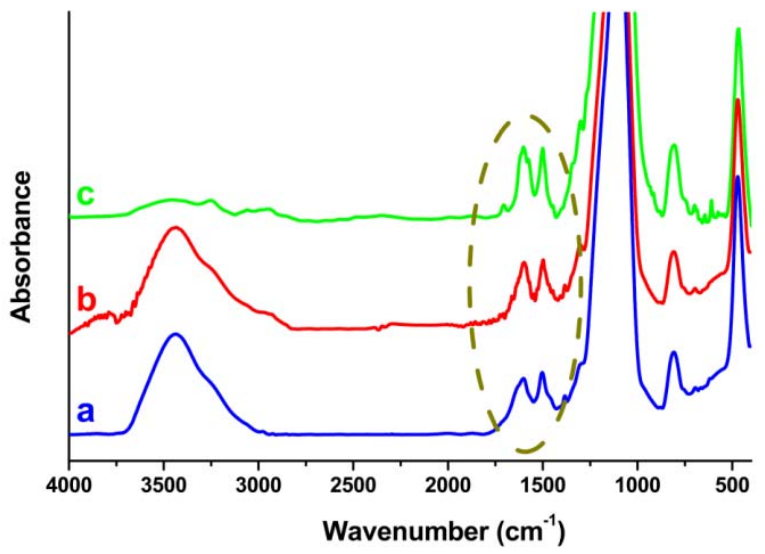

Figure 3. FTIR spectra of NIP@SiOn (a), MIP@SiO 2 (b) and BP4-MIP@SiO (c).

TEM pictures of $\mathrm{ANI} @ \mathrm{SiO}_{2}, \mathrm{MIP} @ \mathrm{SiO}_{2}$ and $\mathrm{NIP} @ \mathrm{SiO}_{2}$ were quite similar. This was in accordance with BET specific area measurements that only revealed a slight loss of surface area upon surface modifications: $A_{\mathrm{sp}}$ was $200 \mathrm{~m}^{2} \cdot \mathrm{g}^{-1}$ for the starting silica, $170 \mathrm{~m}^{2} \cdot \mathrm{g}^{-1}$ after grafting the organosilane, and $140 \mathrm{~m}^{2} \cdot \mathrm{g}^{-1}$ after polymerization of aniline. The primary particles were uniform in size; their mean diameter was $15-25 \mathrm{~nm}$. The pictures were free of characteristic rod-shaped particles of pure PANI crystals. ${ }^{[35]}$

Quantitative determinations of PANI amounts bound to silica were done using thermogravimetric analyses (TGA). For ANI@SiO ${ }_{2}$, the APTMS grafting density of $2.24 \mu \mathrm{mol} \cdot \mathrm{m}^{-2}$ was consistently calculated from the mass loss in TGA and from elemental analyses of $\mathrm{C}$ and $\mathrm{N}$ (section $\mathrm{SI} 2$ of Supporting Information). NIP@SiO 2 and $\mathrm{MIP} @ \mathrm{SiO}_{2}$ materials had similar TGA patterns with one broad step (Figure 4) from 250 to $950{ }^{\circ} \mathrm{C}$ corresponding to the thermal decomposition of PANI strands under their emeraldine base form. TGA of BP4-MIP@SiO ${ }_{2}$ was different because PANI was under its emeraldine salt form and there was BP4 and chloride counter-anions coming from the dopants hydrochloric acid and BP4 sulfonic acid. These anions ensure electroneutrality of the layers. Calculations of chemical compositions of layers from mass losses are reported in section SI3 of Supporting Information; the final results are given in Table 1. The ratio of surface densities of aniline $\left(8.9 \mathrm{\mu mol} \cdot \mathrm{m}^{-2}\right)$ and silane $\left(2.24 \mu \mathrm{mol} \cdot \mathrm{m}^{-2}\right)$ is the mean polymerization degree of aniline; it was $d p=4$. The aniline tetramer is the actual repeat unit of the emeraldine form of PANI; this is the minimum length of PANI strands that allows for electron delocalization in the conductive emeraldine salt form of PANI. ${ }^{36]}$ This is in accordance with IR spectra characteristic of the emeraldine form of PANI through the $\mathrm{C}=\mathrm{C}$ stretching vibrations of quinonoid and benzenoid rings of equal intensities at $1598 \mathrm{~cm}^{-1}$ and $1497 \mathrm{~cm}^{-1}$. Owing to their conductive properties, PANI strands are rigid macromolecules attached to the silica surface by one of their chain ends. Their surface density is that of the starting silane: $2.24 \mu \mathrm{mol} \cdot \mathrm{m}^{-2}$.
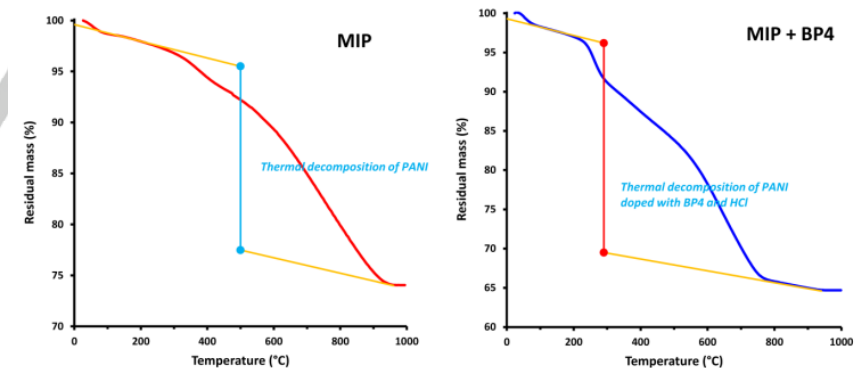

Figure 4. TGA mass losses of $\mathrm{MIP} @ \mathrm{SiO}_{2}$ (left) and $\mathrm{BP} 4-\mathrm{MIP} @ \mathrm{SiO}_{2}$ (right).

Table 1. Surface densities of grafted species as calculated from TGA.

\begin{tabular}{lll}
\cline { 2 - 3 } & $\mathrm{MIP} @ S i O_{2}$ & $\mathrm{BP} 4-\mathrm{MIP} @ \mathrm{SiO}_{2}$ \\
\hline Aniline density $\left(\mu \mathrm{mol} \cdot \mathrm{m}^{-2}\right)$ & 8.9 & 8.9 \\
$d p$ (aniline) & 4.0 & 4.0 \\
$\mathrm{BP} 4^{-}$density $\left(\mu \mathrm{mol} \cdot \mathrm{m}^{-2}\right)$ & & 1.0 \\
$\mathrm{Cl}^{-}$density $\left(\mu \mathrm{mol} \cdot \mathrm{m}^{-2}\right)$ & & 3.45 \\
\hline
\end{tabular}

TGA of BP4-MIP@SiO ${ }_{2}$ revealed that partial doping of PANI by BP4 was effective. Competitive binding of BP4 sulfonic acid and $\mathrm{HCl}$ occurred during aniline polymerization. Stronger binding 
of $\mathrm{Cl}^{-}$anions was observed; the mixed $\mathrm{BP}^{-} / \mathrm{Cl}^{-}$counter-anions contained $20 \%$ of BP4.

The mean thickness of the PANI coating was related to the total mass loss (18\%) as

$t=\frac{\% \text { total mass loss }}{100 \times \rho_{\mathrm{PANI}} \times A_{\mathrm{sp}}} \approx 0.7 \mathrm{~nm}$

where $\rho_{\text {PANI }}$ is the density of PANI $\left(1.36 \mathrm{~g} \cdot \mathrm{cm}^{-3}\right)$. The PANI layer was indeed very thin, close to a 2-dimensional material. Imprints were open structural units with optimum accessibility.

Zeta potential of MIP@SiO $\mathrm{Si}_{2}$ and NIP@SiO ${ }_{2}$ was measured as a function of $\mathrm{pH}$, giving the isoelectric point (iep) of the materials (Figure 5). Both MIP and NIP materials showed identical behavior The isoelectric point was iep $=6.7$, departing a lot from the isoelectric point of bare silica (iep $\approx 2$ ). The present iep was the same as pure emeraldine form of PANI ${ }^{[37]}$ showing that the PANI material was indeed coating the full surface of silica. The surface charge was positive for $\mathrm{pH}<6.7$ and negative for $\mathrm{pH}>6.7$.

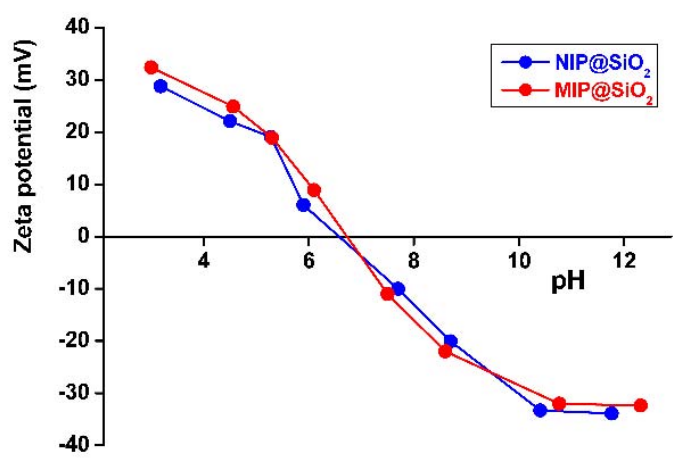

Figure 5. Zeta potential measurements of $\mathrm{MIP} @ \mathrm{SiO}_{2}$ and $\mathrm{NIP@SiO}$ as a function of $\mathrm{pH}$.

\section{Adsorption experiments}

According to the thermodynamic equilibrium between adsorbed and free BP4 molecules, their respective concentrations $\Gamma\left(\mu \mathrm{mol} \cdot \mathrm{m}^{-2}\right)$ and $C\left(\mathrm{~mol} \cdot \mathrm{L}^{-1}\right)$ are related through the "adsorption isotherm". The $\mathrm{pH}$ affects adsorption behavior since it influences electrostatic interactions. Varying the $\mathrm{pH}$ from 2 to 7 shifted the highly positive charge to neutral according to the protonation equilibrium of PANI. BP4 is in mono-anionic form in the full current $\mathrm{pH}$ range ( $\mathrm{pKa}$ values are -0.7 and 7.30 ). ${ }^{[38,39]}$ Variation of temperature allows assessing the relative contributions of enthalpy and entropy to the free energy of adsorption. Finally, kinetics of adsorption is investigated because it is an important parameter for the application of MIP's as chromatographic stationary phases.

As electrostatic interactions are not specific, selective interactions supplement them for BP4 binds to molecular imprints. BP4 non-selectively binds to the positively charged surface off molecular imprints. The contribution to binding by non-selective interactions was assessed by adsorption measurements to NIP@SiO ${ }_{2}$. The comparison of adsorption behavior of MIP and NIP is systematic in works devoted to MIP's: evidence of selective adsorption to molecular imprints is given by the differential adsorption to MIP and NIP. A formal expression of this is the "imprinting factor" (IF) defined as the ratio of adsorptions of MIP and NIP. ${ }^{[40]}$

\section{Thermodynamics of equilibrium adsorption}

Equilibrium adsorption isotherms have been analyzed using the Langmuir isotherm for adsorption to localized molecular imprints and Volmer isotherm for non-selective mobile (nonlocalized) adsorption. Indeed, the non-specific binding off the molecular imprints is a non-localized adsorption to the surface of solid materials. The classical Scatchard ${ }^{[41]}$ and Langmuir ${ }^{[42]}$ models are thermodynamically inadequate because they consider adsorption on localized sites. They have nevertheless been used as a first approach because they are so popular and some readers may wish having a report of them. They are reported in section SI4 and SI5 of Supporting Information. Scatchard plots showed two distinctive straight lines for MIP and a single line for NIP indicative of two kinds of non-equivalent binding sites for MIP ascribed to selective molecular imprints and non-selective adsorption (Figure S7). A simple Langmuir and a bi-Langmuir ${ }^{[43]}$ model were fitted to experimental adsorption data of NIP and MIP. A simple model for non-localized (mobile) adsorption isotherm is given by the Volmer isotherm. ${ }^{[44,45]}$ Even though the Langmuir model fits quite nicely to experimental data, the Volmer model is preferred because it matches the physicochemical mechanism of non-selective adsorption as a layer of mobile adsorbed molecules.

\section{The Langmuir-Volmer model}

As the Volmer adsorption isotherm is not currently used in the field of adsorption to MIP's, a brief introduction of it is given. The starting point is the 2-dimensional analogue of the van der Waals equation of state:[46]

$\Pi(A-\beta)=n k T$

where $\Pi$ is the surface pressure, $A$ is the area, and $\beta$ is the molecular size. The pressure term of van der Waals related to lateral interactions is neglected. Following de Boer, ${ }^{[4]}$ combination of Eq 3 and the Gibbs-Duhem equation yields the Volmer adsorption isotherm

$C=\frac{1}{K} \frac{\theta}{1-\theta} \mathrm{e}^{\frac{\theta}{1-\theta}}$

where $\theta$ is the surface coverage, $\theta=\Pi \Gamma_{\max }$, and $K$ is the binding constant for adsorption equilibrium. The Volmer isotherm differs from the Langmuir one by the supplementary term $\mathrm{e}^{\theta /(1-\theta)}$.

The specific adsorption on molecular imprints is localized, so that it was modeled by a Langmuir adsorption isotherm

$\Gamma_{\mathrm{s}}=\Gamma_{\mathrm{max}, \mathrm{s}} \frac{K_{\mathrm{S}} C}{1+K_{\mathrm{s}} C}$

The theoretical adsorption isotherms were fitted to the experimental data by minimizing the root-mean-square deviation ( $r m s$ with $N$ data points and $p$ variables, Eq 6 ) by non-linear regression. The Volmer isotherm was used for non-specific adsorption isotherms of NIP, and the sum of a Langmuir and a Volmer isotherm was used for the non-specific and specific (to molecular imprints) contributions to adsorption for MIP. The variables are $K_{\mathrm{s}}, \Gamma_{\text {max,s }}, K_{\mathrm{ns}}$ and $\Gamma_{\text {max,ns }}$ for specific and non-specific binding constant and adsorption at full coverage. 
$r m s=\sqrt{\frac{1}{(N-p)} \sum_{i=1}^{N}\left(\Gamma_{\text {exp }, i}-\Gamma_{\text {calc }, i}\right)^{2}}$

Eq 6

\section{Effect of $\mathrm{pH}$}

In all cases binding of BP4 was stronger to MIP than NIP, providing evidence for the presence of molecular imprints (Figure 6). Binding was stronger in acidic medium ( $\mathrm{pH} 2)$ due to the predominance of electrostatic attractions to positive charges of both MIP and NIP. At higher $\mathrm{pH}$, adsorption capacity of MIP was larger than NIP, especially at $\mathrm{pH} 4$ used for the synthesis medium of adsorbents. The imprinting effect is more pronounced when re-binding of the template is operated at the same $\mathrm{pH}$ than that used during the synthesis of the adsorbent. ${ }^{[40]} \mathrm{At} \mathrm{pH} 7$ close to the isoelectric point where the surface is neutral, electrostatic attraction with the anionic BP4 was disabled and a low adsorption capacity was observed for both MIP@SiO ${ }_{2}$ and NIP@SiO ${ }_{2}$. The best fits of the Volmer model to NIP@ $\mathrm{SiO}_{2}$ and of the combined Langmuir-Volmer model to $\mathrm{MIP} @ \mathrm{SiO}_{2}$ (Figure 6) yielded the adsorption parameters given in Table 2 .

The variations of thermodynamic parameters with respect to $\mathrm{pH}$ are presented in Figure 7. The adsorbed amount on $\mathrm{NIP} @ \mathrm{SiO}_{2}, \Gamma_{\mathrm{max}, \mathrm{ns}}$, increased in acidic medium because the density of positively charged groups increased. Conversely, the affinity of BP4 did not vary with respect to $\mathrm{pH}$ ( $K_{\mathrm{ns}}$ did not vary).
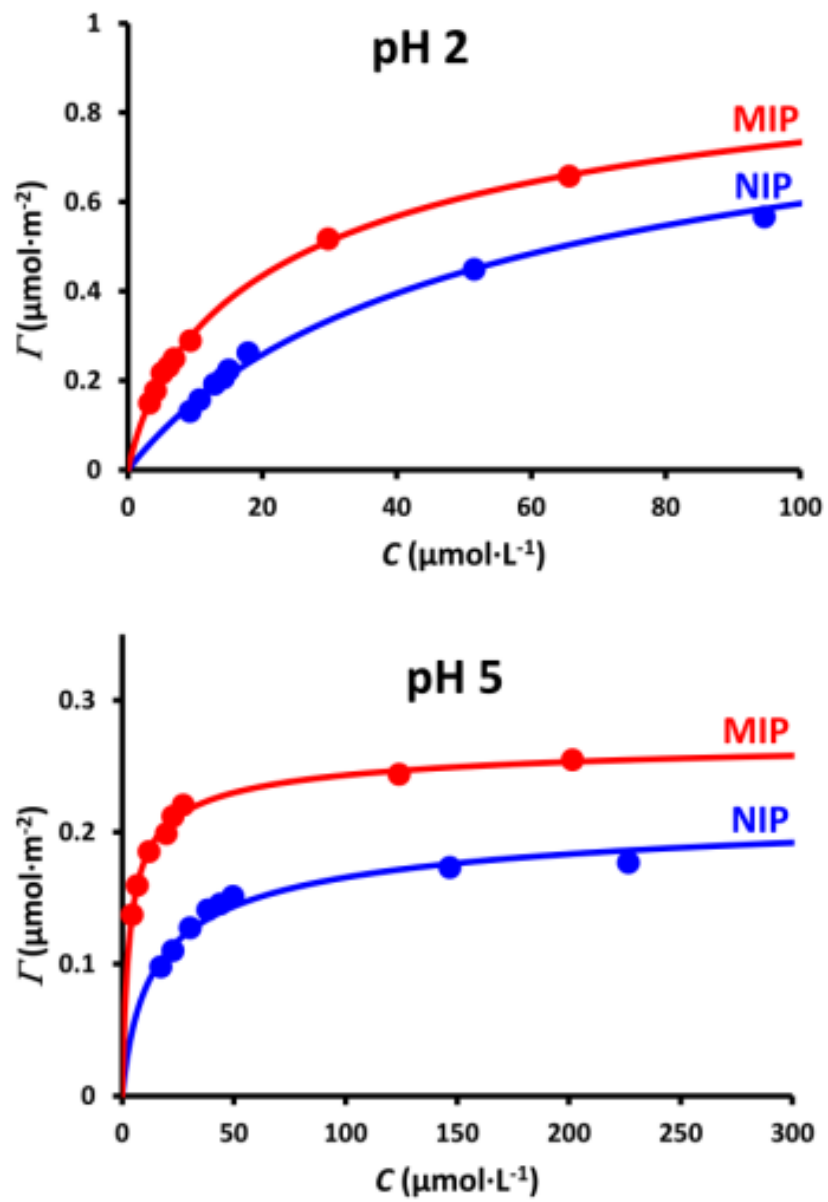

So non-selective binding was higher in acidic medium because the electrical charge was larger; but binding was not stronger. Indeed, the charge density of the solid surface does not increase the interactions because binding is an anion exchange of BP4 for chloride. The driving force for excess adsorption of BP4 is nonelectrostatic; it may come from hydrophobic, dispersion or hydrogen bonding interactions. The parameters of non-selective binding to MIP@SiO ${ }_{2}$ off the molecular imprints were almost the same as for NIP@SiO $2 . \Gamma_{\text {max,s }}$ was constant because the density of molecular imprints does not vary against $\mathrm{pH}$. This surface density $\left(\Gamma_{\mathrm{max}, \mathrm{s}}=0.2 \mu \mathrm{mol} \cdot \mathrm{m}^{-2}\right)$ was lower than that of BP4 at the end of the synthesis as inferred from TGA $\left(1.0 \mu \mathrm{mol} \cdot \mathrm{m}^{-2}\right)$. Only part of the BP4 molecules acting as dopants of PANI had created molecular imprints that resisted extraction with ammonium hydroxide. The balance of adsorbed amounts was correct as the sum of $\Gamma_{\max , \text { ns }}$ and $\Gamma_{\max , \mathrm{s}}$ of MIP@ $@ \mathrm{SiO}_{2}$ was equal to $\Gamma_{\max , \text { ns }}$ of $\mathrm{NIP} @ \mathrm{SiO}_{2}$ (Figure 7A). Finally, the affinity for molecular imprints given by $K_{\mathrm{s}}$ was maximum at $\mathrm{pH} 4-5$ (Figure $7 \mathrm{~B}$ ). The interaction of $\mathrm{BP} 4$ with molecular imprints was optimum at the $\mathrm{pH}$ of the synthesis process. The complex set of molecular interactions depending on electron density distribution within the molecular imprint does depend on $\mathrm{pH}$.
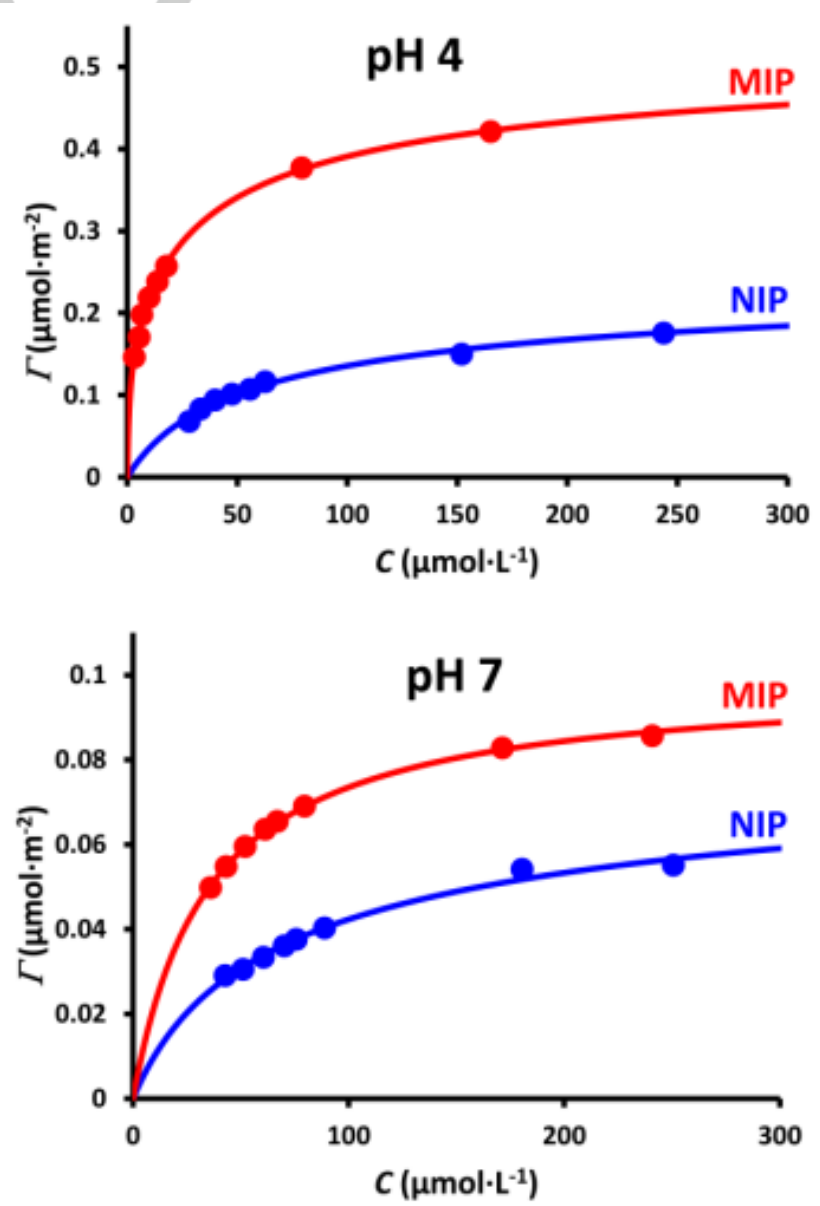

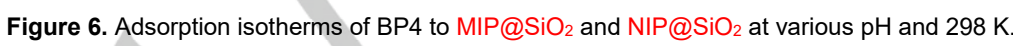

Table 2. Parameters of the best fits of the Volmer and Langmuir-Volmer models to experimental adsorption isotherms of BP4 to NIP@SiO 2 and MIP@SiO ${ }_{2}$ at 298 K.

\begin{tabular}{|c|c|c|c|c|c|c|c|c|}
\hline \multicolumn{3}{|c|}{$\mathrm{NIP} @ \mathrm{SiO}_{2}$} & \multicolumn{6}{|c|}{$\mathrm{MIP} @ \mathrm{SiO}_{2}$} \\
\hline$K_{\mathrm{ns}}$ & $\log \left(K_{\mathrm{ns}}\right)$ & $\Gamma_{\max , \mathrm{ns}}\left(\mu \mathrm{mol} \cdot \mathrm{m}^{-2}\right)$ & $K_{\mathrm{s}}$ & $\log \left(K_{s}\right)$ & $\Gamma_{\max , \mathrm{s}}\left(\mu \mathrm{mol} \cdot \mathrm{m}^{-2}\right)$ & $K_{\mathrm{ns}}$ & $\log \left(K_{\mathrm{ns}}\right)$ & $\Gamma_{\max , \mathrm{ns}}\left(\mu \mathrm{mol} \cdot \mathrm{m}^{-2}\right)$ \\
\hline
\end{tabular}




\begin{tabular}{|c|c|c|c|c|c|c|c|c|c|}
\hline pH 2 & 12,800 & 4.11 & 1.50 & 202,000 & 5.30 & 0.23 & 18,900 & 4.28 & 1.14 \\
\hline pH 4 & 12,900 & 4.11 & 0.34 & 695,000 & 5.84 & 0.18 & 17,000 & 4.23 & 0.49 \\
\hline pH 5 & 58,000 & 4.76 & 0.28 & 570,000 & 5.76 & 0.18 & 20,000 & 4.30 & 0.15 \\
\hline pH 7 & 10,900 & 4.04 & 0.11 & 29,000 & 4.46 & 0.09 & 19,000 & 4.28 & 0.01 \\
\hline
\end{tabular}
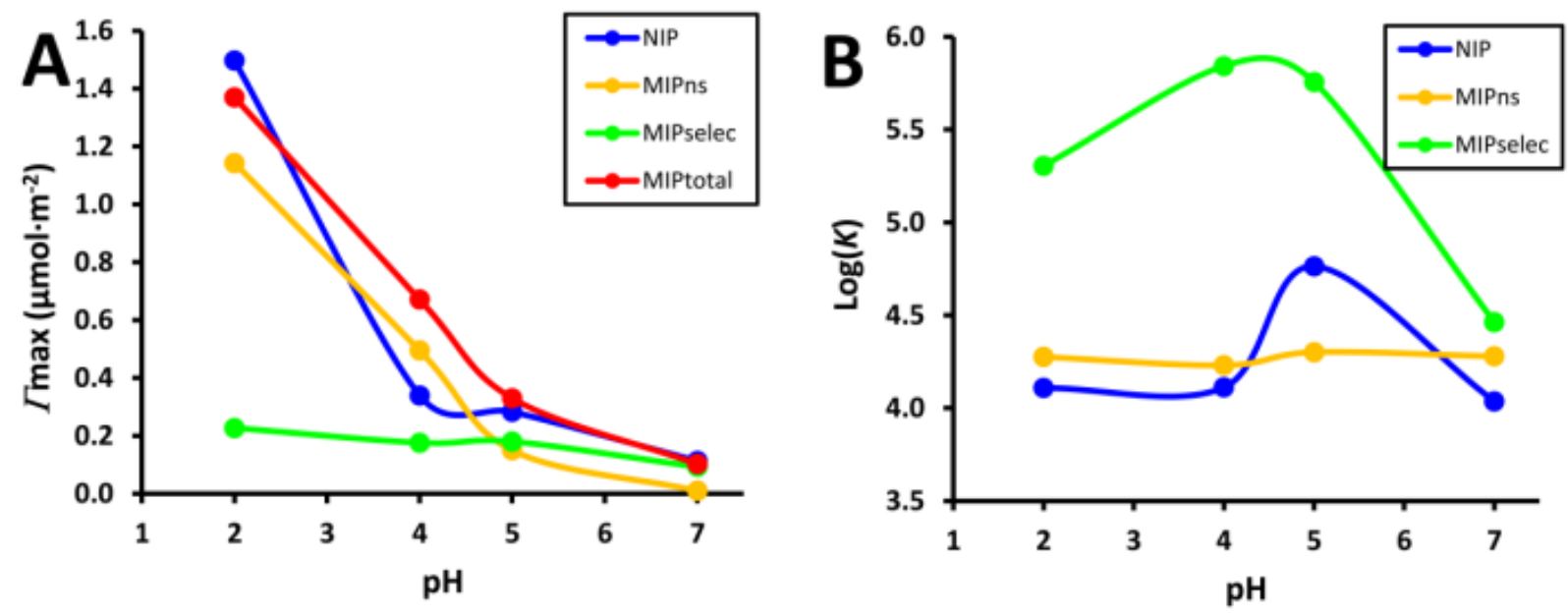

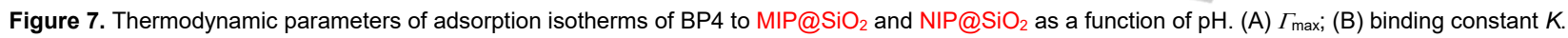

Selectivity of binding is often characterized by the "Imprinting Factor" (IF) defined as the ratio of adsorbed amounts to MIP and NIP. ${ }^{[40]}$ This ratio strongly depends on the concentration of adsorbing molecules. It is usually defined for a large enough concentration where adsorption is at the plateau $\left(\Gamma=\Gamma_{\max }\right)$ for it does not depend on concentration. This is far off the concentration range of analytical applications such as chromatographic separations. The present thermodynamic characterization of MIP and NIP properties allows a thermodynamic definition of $I F$ as the ratio of the binding constants $K_{\mathrm{s}} / K_{\mathrm{ns}}$. Such $I F$ was maximum at $\mathrm{pH}$ 4. Non-selective binding was prevailing in acidic medium and selective binding turned predominant as $\mathrm{pH}$ increased. The highest ratio $\Gamma_{\max , \mathrm{s}} / \Gamma_{\max , \mathrm{ns}}$ was reached at $\mathrm{pH} 7$ because nonselective binding was weak and the density of imprints for selective binding remained constant. However, the affinity constant for imprints $K_{\mathrm{s}}$ strongly decreased at high $\mathrm{pH}$, which allows using the $\mathrm{pH}$ as a mean for releasing bound BP4 molecules. Loss of affinity in basic medium is obviously caused by the vanishing electrostatic contribution; a reversible deformation of the molecular imprints may also occur as reported in case of imprinted cross-linked amylose gels. ${ }^{[48]}$

\section{Enthalpic and entropic contributions to the standard free energy of adsorption}

The standard Gibbs free energy $\Delta_{\text {ads }} G^{\circ}$, enthalpy $\Delta_{\text {ads }} H^{\circ}$ and entropy $\Delta_{\text {ads }} S^{\circ}$ of adsorption were calculated from the binding constant determined at several temperatures and the van't Hoff equation for each type of binding type ( $i=\mathrm{s}$ or ns):

$$
\ln \left(K_{i}\right)=\frac{\Delta_{\mathrm{ads}} S_{i}^{0}}{R}-\frac{\Delta_{\mathrm{ads}} H_{i}^{0}}{R T}
$$

The van't Hoff plots for the selective and non-selective adsorption processes were linear (Figure 8), showing that $\Delta_{\text {ads }} H^{\circ}$ and $\Delta_{\text {ads }} S^{\circ}$ did not depend on temperature in the studied temperature range (Table 3 ).

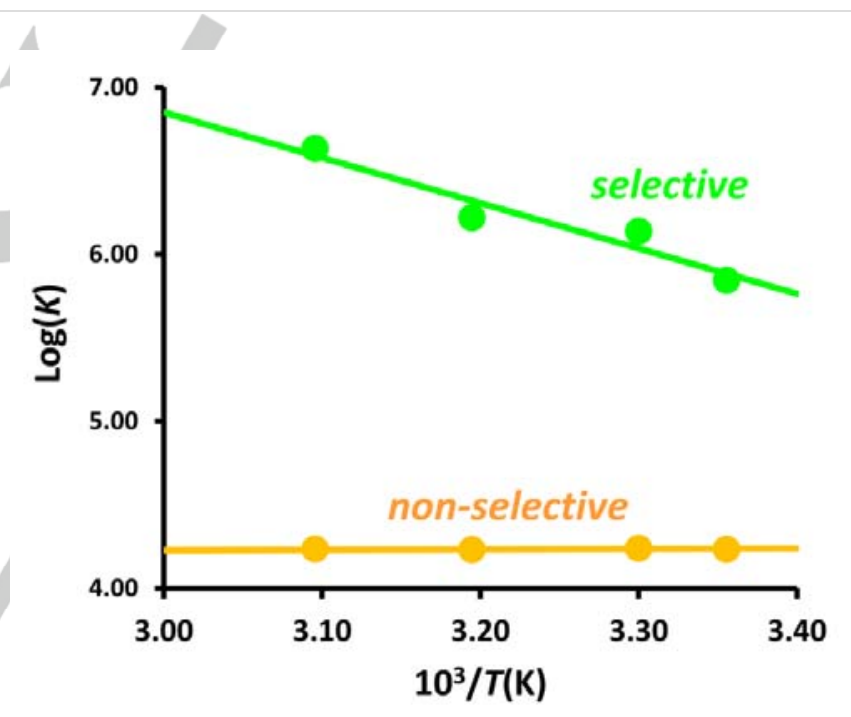

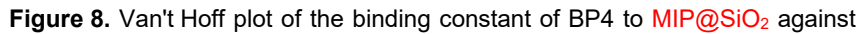
inverse temperature at $\mathrm{pH} 4$.

Table 3.Standard adsorption enthalpy and entropy, $\Delta_{\text {ads }} H^{\circ}$ and $\Delta_{\text {ads }} S^{\circ}$, for the

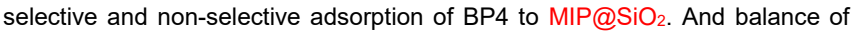
$\Delta_{\text {ads }} G^{\circ}, \Delta_{\text {ads }} H^{\circ}$ and $-T \Delta_{\text {ads }} S^{\circ}$ at $298 \mathrm{~K}$.

\begin{tabular}{llcccc}
\hline & $\begin{array}{c}\Delta_{\text {ads }} H^{\circ} \\
\left(\mathrm{kJ} \cdot \mathrm{mol}^{-1}\right)\end{array}$ & $\begin{array}{c}\Delta_{\text {ads }} \mathrm{S}^{\circ} \\
\left(\mathrm{J} \cdot \mathrm{mol}^{-1} \cdot \mathrm{K}^{-1}\right.\end{array}$ & \multicolumn{2}{c}{$\begin{array}{c}\text { Contributions to } \Delta_{\text {ads }} \mathrm{G}^{\circ} \\
\left(\mathrm{kJ} \cdot \mathrm{mol}^{-1}\right)\end{array}$} \\
\hline selective & 52.0 & 287 & $\Delta_{\text {ads }} \mathrm{G}^{\circ}$ & $\Delta_{\text {ads }} H^{\circ}$ & $-T \Delta_{\text {ads }} S^{\circ}$ \\
non-selective & -0.1 & 80.6 & -33.6 & 52.0 & -85.6 \\
\hline
\end{tabular}

The non-selective adsorption was athermal $\left(\Delta_{\text {ads }} H^{\circ} \approx 0\right)$, so the adsorption was entropic in origin. The entropic contribution may be viewed as the result of mixing BP4 and chloride ions in the adsorbed layer. Entropy of mixing is always positive. The athermal feature may result from compensation of exothermic and endothermic contributions.

The selective adsorption was endothermic and absolute value of the entropic contribution $T \Delta_{\text {ads }} S^{\circ}$ was larger than the enthalpic. The balance is predominance of entropic contribution. The large positive entropy may suggest that adsorption of BP4 relaxed PANI 
strands to their original configuration around the molecular imprints because they have been created in contact with BP4. On the contrary, chloride ions do not fit molecular imprints frozen in constrained configuration after washing off BP4. The enthalpy of adsorption has obvious contributions from hydrogen bonding because of the presence of a hydroxy group in BP4. Stronger endothermic contributions operate for the net result can be a positive value of $\Delta_{\text {ads }} H^{\circ}$. The hydrophobic interaction is a possible origin of the endothermic nature of adsorption. Indeed hydrophobic interaction is characterized by both positive enthalpy and entropy of transfer from water to organic medium. ${ }^{[49]}$ The microscopic origin of such phenomenon is the formation of a water shell around hydrophobic solutes having a larger number of hydrogen bonds than in normal liquid water. Such shell of structured water has been termed as "iceberg" by Frank and Evans $^{[50]}$ because it is close to the structure of ice. Adsorption of hydrophobic solutes from water to a hydrophobic surface releases the iceberg of structured water by breaking excess hydrogen bonds, giving an endothermic contribution to the enthalpy of adsorption. The BP4 molecule is obviously much more hydrophobic than chloride ions.

\section{Kinetics of adsorption}

The kinetics of adsorption is of high practical importance in applications to analysis such as liquid chromatographic separations and sample pre-concentration in solid phase microextraction devices (SPME). Fast adsorption allows high flow rate and short duration of analyses. Adsorption kinetics of BP4 onto $\mathrm{MIP} @ \mathrm{SiO}_{2}$ and $\mathrm{NIP} @ \mathrm{SiO}_{2}$ materials was measured for dilute solutions of BP4 of concentration within the ascending part of the adsorption isotherm such that the adsorbent cannot be saturated (Figure 9). Adsorption was quite fast as more than $90 \%$ of equilibrium adsorption was reached within few minutes. Fast kinetics was ensured by using a thin film of MIP bound to a solid support of porosity designed for chromatographic applications.
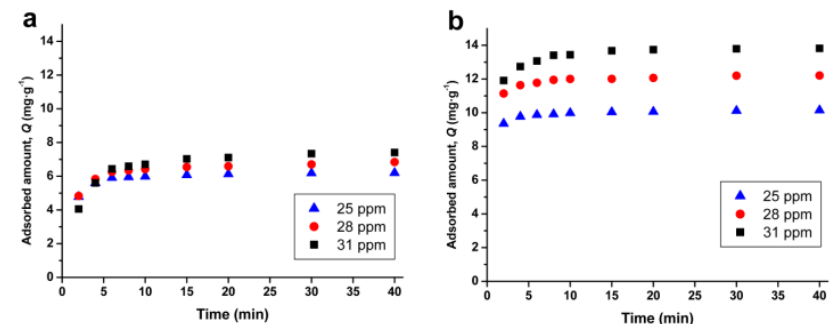

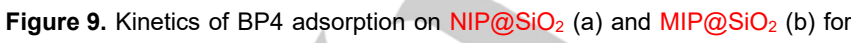
three concentrations at $\mathrm{pH} 4$.

Early MIPs were made of polymer beads ${ }^{[51]}$ prepared by radical polymerization in the presence of a porogen. The porous structure was designed such as providing a large accessible specific surface area that ensured a high binding capacity. ${ }^{[52]}$ But the drawback with regards to some applications was slow binding kinetics because the pore sizes were too small. A typical time scale taken from the scarce experimental data is from $1 \mathrm{~h}$ to days. ${ }^{[53-55]}$ These features are shared by sol-gel materials, ${ }^{[56,57]}$ mesoporous materials, ${ }^{[58]}$ and aggregated nanoparticles. ${ }^{[59,60]}$ Fast adsorption was observed in cases where pores have large sizes. ${ }^{[61]}$ So far, thin layers of MIPs have mainly been developed for their application to chemical sensors (thin coating cast on an electrode or a transducing device). ${ }^{[18-22]}$ Hence the present fast adsorption kinetics came from the favorable porosity of the solid support and the thin thickness of the MIP layer, in accordance with literature data.

\section{General Discussion and}

\section{Conclusion}

Molecular imprinted materials have been prepared with no need for cross-linking agent by using a thin layer of a rigid polymer (PANI) bound to a solid support. Both the stiffness of the PANI strands and the proximity of the solid surface contribute to the rigidity of the layer that keeps the molecular imprints as the template molecules are washed off. The structure of the grafted layer is a dense polymer brush ${ }^{[62,63]}$ with strong lateral stacking of PANI strands and packing defects where molecular imprints are frozen. Such defects are similar to grain boundaries of a polycrystalline material, they allow for molecular imprints but would not be suitable for keeping the shape of large templates such a nanoparticles or proteins. ${ }^{[64,65]} \mathrm{A}$ method that may be felt similar is building a self-assembled monolayer (SAM) of fatty thiol molecules on gold surface where the imprints are the "shadows" of the template molecules interacting with the gold surface that leave holes inside the layer. ${ }^{[66-68]}$ The present process relies on quite a different phenomenon where imprints are defects in the structure where target molecules interact with the polymer material. Figure 10 is a sketch showing a perspective of the MIP structure made of short PANI strands at close contact because of their strong lateral interactions.

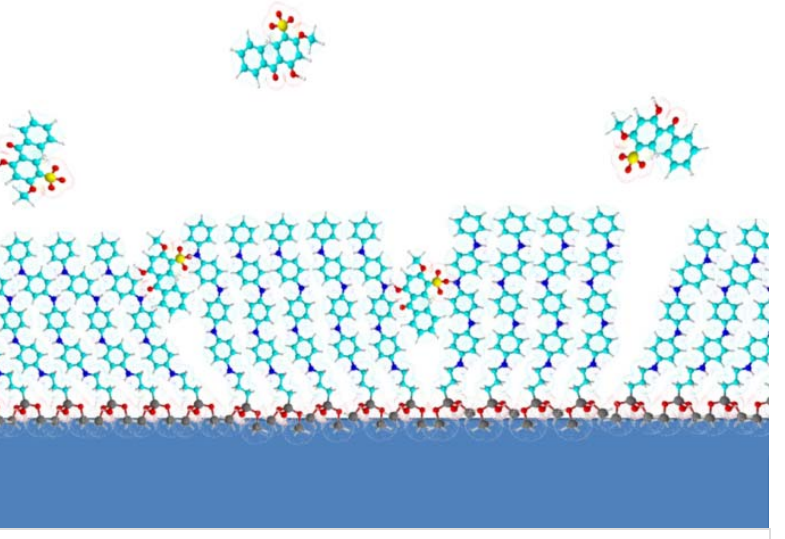

Figure 10. Structure of a MIP@ $\mathrm{SiO}_{2}$ as a thin film attached to the silica surface. Selectively adsorbed BP4 molecules bind to molecular imprints frozen by lateral interactions between PANI strands. Colors for atoms: Carbon: light blue, Hydrogen: grey, Nitrogen: dark blue, Oxygen: red, Sulfur: yellow. Dark blue material at bottom is the silica support.

The driving force for adsorption is electrostatic. Affinity for specific binding weakens under basic conditions $(\mathrm{pH} 7)$ that electrostatic interactions vanish. Specificity is lost when very strong electrostatic interactions predominate in acidic medium. Hence, there is an optimum $\mathrm{pH}$ which was at $\mathrm{pH} \mathrm{4-5}$ in the present case.

A correct thermodynamic approach that accounts for the mobility in non-specific binding was proposed using the Volmer adsorption isotherm. Non-specific interactions are of entropic nature, which is expected for an anion exchange phenomenon driven by electrostatics. The supplementary enthalpic contribution 
for specific interactions with molecular imprints shows that specificity comes from the combination of electrostatic and nonelectrostatic interactions.

\section{Acknowledgements}

Stays of Cherifa Ayadi at University of Lyon during her PhD were supported by grants "Bourse d'alternance" from the Tunisian Ministry of Higher Education and Scientific Research.

Keywords: Adsorption • Imprinting • Surface chemistry • Thermodynamics

\section{Supporting information: SI file}

[1] B. Sellergren (Ed.), Molecularly Imprinted Polymers. Man-made Mimics of Antibodies and their Applications in Analytical Chemistry. Elsevier, Amsterdam, 2001.

[2] C. Alvarez-Lorenzo, A. Concheiro (Eds.), Handbook of Molecularly Imprinted Polymers. Smithers Rapra, Shawbury, UK, 2013.

[3] G. Wulff, A. Sarhan, Angew. Chem. Int. Ed. Engl. 1972, 11, 341; Angew. Chem. 1972, 84, 364.

[4] G. Wulff, A. Sarhan, K. Zabrocki, Tetrahedron Lett. 1973, 44, 4329-4332.

[5] K. Haupt, Analyst 2001, 126, 744-756.

[6] A. G. Mayes, K. Mosbach, TrAC Trends Anal. Chem. 1997, 16, 321-332.

[7] S. Li, S. Cao, S. A. Piletsky, A. P. F. Turner (Eds.), Molecularly Imprinted Catalysts. Principles, Syntheses, and Applications. Elsevier, Amsterdam, 2016.

[8] S. Li, Y. Ge, A. A. Piletsky, J. Lunec (Eds.), Molecularly Imprinted Sensors: Overview and Applications. Elsevier, Amsterdam, 2012.

[9] B. Mattiasson, L. Ye (Eds.), Molecularly Imprinted Polymers in Biotechnology, Adv. Biochem. Eng. Biotechnol. Vol. 150, Springer, Heidelberg, 2015.

[10] G. Wulff, Angew. Chem. Int. Ed. 1995, 34, 1812-1832; Angew. Chem. 1995, 107, 1958-1979.

[11] G. Wulff, T. Gross, R. Schönfeld, Angew. Chem. Int. Ed. Engl. 1997, 36 1962-1964; Angew. Chem. 1997, 109, 2050-2052.

[12] G. Wulff, Chem. Rev. 2002, 102, 1-27.

[13] J. Wang, P. A. G. Cormack, D. C. Sherrington, E. Khoshdel, Angew. Chem. Int. Ed. 2003, 42, 5336-5338; Angew. Chem. 2003, 115, 5494 5496.

[14] J. L. Urraca, A. J. Hall, M. C. Moreno-Bondi, B. Sellergren, Angew. Chem. Int. Ed. 2006, 45, 5158-5161; Angew. Chem. 2006, 118, 5282-5285.

[15] E. Yilmaz, K. Haupt, K. Mosbach, Angew. Chem. Int. Ed. 2000, 39, 2115 2118; Angew. Chem. 2000, 112, 2178-2181.

[16] A. Anene, R. Kalfat, Y. Chevalier, S. Hbaieb, Colloids Surf. A 2016, 497, 293-303.

[17] A. Anene, K. Hosni, Y. Chevalier, R. Kalfat, S. Hbaieb, Food Control 2016, 70, 90-95.

[18] C. Ayela, F. Vandevelde, D. Lagrange, K. Haupt, L. Nicu, Angew. Chem. Int. Ed. 2007, 46, 9271-9274; Angew. Chem. 2007, 119, 9431-9434.

[19] P. K. Ivanova-Mitseva, A. Guerreiro, E. V. Piletska, M. J. Whitcombe, Z. Zhou, P. A. Mitsev, F. Davis, S. A. Piletsky, Angew. Chem. Int. Ed. 2012 51, 5196-5199; Angew. Chem. 2012, 124, 5286-5289.

[20] W. Wan, M. Biyikal, R. Wagner, B. Sellergren, K. Rurack, Angew. Chem. Int. Ed. 2013, 52, 7023-7027; Angew. Chem. 2013, 125, 7161-7165.

[21] X.-A. Ton, B. Tse Sum Bui, M. Resmini, P. Bonomi, I. Dika, O. Soppera, K. Haupt, Angew. Chem. Int. Ed. 2013, 52, 8317-8321; Angew. Chem. 2013, 125, 8475-8479.

[22] G. Pan, S. Shinde, S. Y. Yeung, M. Jakštaitè, Q. Li, A. Gjörloff Wingren, B. Sellergren, Angew. Chem. Int. Ed. 2017, 56, 15959-15963; Angew. Chem. 2017, 129, 16175-16179.

[23] M. Krause, A. Klit, M. B. Jensen, T. Søeborg, H. Frederiksen, M. Schlumpf, W. Lichtensteiger, N. E. Skakkebaek, K. T. Drzewiecki, Int. J. Androl. 2012, 35, 424-436.
[24] P. Y. Kunz, H. F. Galicia, K. Fent, Toxicol. Sci. 2006, 90, 349-361.

[25] R. Danovaro, L. Bongiorni, C. Corinaldesi, D. Giovannelli, E. Damiani, P. Astolfi, L. Greci, A. Pusceddu, Environ. Health Perspect. 2008, 116, 441447.

[26] O. T. Ikkala, L.-O. Pietilä, P. Passiniemi, T. Vikki, H. Österholm, L. Ahjopalo, J.-E. Österholm, Synth. Met. 1997, 84, 55-58.

[27] K. Sreenivasan, React. Funct. Polym. 2007, 67, 859-864.

[28] J. Luo, J. Sun, J. Huang, X. Liu, Chem. Eng. J. 2016, 283, 1118-1126.

[29] C. Ayadi, A. Anene, R. Kalfat, Y. Chevalier, S. Hbaieb, Colloids Surf. A 2019, 567, 32-42.

[30] E. P. Plueddemann, Silane Coupling Agents. Plenum Press, New York, 1982.

[31] S. Hbaieb, R. Kalfat, Y. Chevalier, Int. J. Pharm. 2012, 439, 234-245.

[32] H. Okamoto, T. Kotaka, Polymer 1998, 39, 4349-4358.

[33] N. Gospodinova, L. Terlemezyan, Prog. Polym. Sci. 1998, 23, 14431484.

[34] C. D. Ki, C. Oh, S.-G. Oh, J. Y. Chang, J. Am. Chem. Soc. 2002, 124, 14838-14839.

[35] D. Li, R. B. Kaner, J. Am. Chem. Soc. 2006, 128, 968-975

[36] Y. Wang, H. D. Tran, L. Liao, X. Duan, R. B. Kaner, J. Am. Chem. Soc. 2010, 132, 10365-10373.

[37] R. L. Li, C.-W. Lin, Y. Shao, C. W. Chang, F.-K. Yao, M. D. Kowal, H Wang, M. T. Yeung, S.-C. Huang, R. B. Kaner, Polymers 2016, 8, 410.

[38] N. Negreira, I. Rodríguez, M. Ramil, E. Rubí, R. Cela, Anal. Chim. Acta 2009, 654, 162-170.

[39] E. De Laurentiis, M. Minella, M. Sarakha, A. Marrese, C. Minero, G Mailhot, M. Brigante, D. Vione, Water Res. 2013, 47, 5943-5953.

[40] R. J. Ansell, Adv. Biochem. Eng. Biotechnol. 2015, 150, 51-93.

[41] G. Scatchard, Ann. New York Acad. Sci. 1949, 51 (4), 660-672.

[42] I. Langmuir, J. Am. Chem. Soc. 1918, 40, 1361-1403.

[43] H. Kim, K. Kaczmarski, G. Guiochon, J. Chromatogr. A 2006, 1101, 136152.

[44] S. Ross, J.P. Olivier, On Physical Adsorption. Wiley, New York, 1964, p. 17.

[45] D. M. Ruthven, Principles of Adsorption and Adsorption Processes. Wiley, New York, 1984, p. 69.

[46] M. Volmer, Z. Phys. Chem. 1925, 115, 253-260

[47] J. H. de Boer, The Dynamical Character of Adsorption. Clarendon Press, Oxford, 1953, p. 170.

[48] Y. Kanekiyo, R. Naganawa, H. Tao, Angew. Chem. Int. Ed. 2003, 42, 3014-3016; Angew. Chem. 2003, 115, 3122-3124.

[49] C. Tanford, The Hydrophobic Effect: Formation of Micelles and Biological Membranes. $2^{\text {nd }}$ edition, Wiley, New York, 1980, pp. 21-26.

[50] H. S. Frank, M. W. Evans, J. Chem. Phys. 1945, 13, 507-532.

[51] A. G. Mayes, Polymerisation Techniques for the Formation of Imprinted Beads. In Molecularly Imprinted Polymers. Man-made Mimics of Antibodies and their Applications in Analytical Chemistry (Ed.: B. Sellergren), Elsevier, Amsterdam, 2001, Chap. 12, pp. 305-324.

[52] B. Sellergren, A. J. Hall, Fundamental Aspects of Imprinted Network Polymers. In Molecularly Imprinted Polymers. Man-made Mimics of Antibodies and their Applications in Analytical Chemistry (Ed.: B. Sellergren), Elsevier, Amsterdam, 2001, Chap. 2, pp. 31-35.

[53] Y. Zhou, W. Wu, M. Liu, Y. Zhou, S. Mei, J. Sep. Sci. 2014, 37, 29402946.

[54] P. Narula, V. Kaur, R. Singh, S. K. Kansal, J. Sep. Sci. 2014, 37, 33303338.

[55] W. Li, S. Li, G. Luo, K. Ding, Bull. Korean Chem. Soc. 2007, 28, 13461352.

[56] S. Xu, L. Chen, J. Li, Y. Guan, H. Lu, J. Hazardous Mater. 2012, $237-$ 238, 347-354

[57] C. R. Teixeira Tarley, F. N. Andrade, H. de Santana, D. A. Morozin Zaia, L. A. Beijo, M. G. Segatelli, React. Funct. Polym. 2012, 72, 83-91.

[58] J. Tan, H.-F. Wang, X.-P. Yan, Anal. Chem. 2009, 81, 5273-5280.

[59] R. Suedee, V. Seechamnanturakit, A. Suksuwan, B. Canyuk, Int. J. Mol. Sci. 2008, 9, 2333-2356.

[60] J. Pan, H. Yao, W. Guan, H. Ou, P. Huo, X. Wang, X. Zou, C. Li, Chem. Eng. J. 2011, 172, 847-855.

[61] M. A. Abd El-Aal, M. A. Al-Ghobashy, F. A. Fathalla, Y. S. El-Saharty, J. Chromatogr. B 2017, 1046, 34-47. 
[62] B. Zhao, W. J. Brittain, Prog. Polym. Sci. 2000, 25, 677-710.

[63] A. Wittemann, M. Drechsler, Y. Talmon, M. Ballauff, J. Am. Chem. Soc. 2005, 127, 9688-9689.

[64] S. Gam-Derouich, C. Bourdillon, S. Lakhdar Chaouche, L. Coolen, A. Maître, C. Mangeney, C. Schwob, Angew. Chem. Int. Ed. 2017, 56, 9710-9714; Angew. Chem. 2017, 129, 9842-9846.

[65] R. Mahajan, M. Rouhi, S. Shinde, T. Bedwell, A. Incel, L. Mavliutova, S. Piletsky, I. A. Nicholls, B. Sellergren, Angew. Chem. Int. Ed. 2019, 58, 727-730; Angew. Chem. 2019, 131, 737-740.

[66] S. A. Piletsky, E. V. Piletskaya, T. A. Sergeyeva, T. L. Panasyuk, A. V. El'skaya, Sensors Actuators B 1999, 60, 216-220.

[67] V. M. Mirsky, T. Hirsch, S. A. Piletsky, O. S. Wolfbeis, Angew. Chem. Int. Ed. 1999, 38, 1108-1110.

[68] S. Balamurugan, D. A. Spivak, J. Mol. Recognit. 2011, 24, 915-929. 


\section{Entry for the Table of Contents}

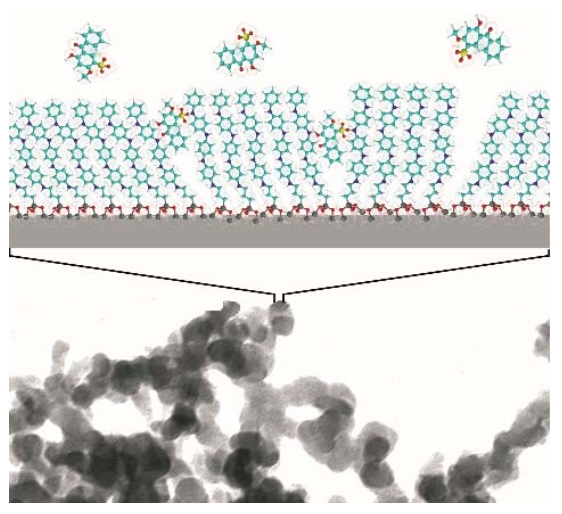

Molecularly Imprinted Polymer materials with no need for cross-linking are reported. Lateral interactions between stiff polyaniline chains grafted to a porous silica support ensure the rigidity that keeps the shape-memory of guest molecules. 


\title{
SUPPORTING INFORMATION
}

\section{Molecular Imprints Frozen by Strong Intermolecular Interactions in Place of Cross-linking}

\author{
Cherifa Ayadi $^{1,2,3}$, Amira Anene ${ }^{1}$, Rafik Kalfat ${ }^{1}$, Yves Chevalier ${ }^{2, *}$, Souhaira Hbaieb ${ }^{1,3, *}$ \\ 1- Laboratoire Méthodes et Techniques d'Analyse, INRAP, Biotechpole Sidi-Thabet, 2020 Ariana, Tunisia. \\ 2- Laboratoire d'Automatique, de Génie des Procédés et de Génie Pharmaceutique; UMR 5007 CNRS, Université de \\ Lyon 1, 69622 Villeurbanne, France. \\ 3- Université Tunis El Manar, Faculté des Sciences de Tunis, Campus Universitaire El Manar, Tunisia.
}

\section{SI1. Materials and Methods}

\section{Reagents and Materials}

Fumed silica Cab-O-Sil with mean particle size of $12 \mathrm{~nm}$ and specific area $200 \mathrm{~m}^{2} \cdot \mathrm{g}^{-1}$ was obtained from Cabot Corporation (Tuscold, ILL). Benzophenone-4 (BP4) was purchased from TCI Chemicals. Aniline, N-[3-(trimethoxysilyl)propyl]aniline (APTMS) and diisopropylethylamine (DIEA) were supplied by Sigma-Aldrich. HPLC grade MeOH was purchased from Fisher Scientific. Other reagents were of analytical grade and used as received. Milli-Q water of $18 \mathrm{M} \Omega \cdot \mathrm{cm}$ resistivity was used in all experiments.

\section{Preparation of surface imprinted polyaniline (PANI@MIP)}

The silica support was first grafted with organosilane containing aniline. The following recipe was selected after preliminary experiments reported in section SI5. $5 \mathrm{~g}$ of dried silica was dispersed with a magnetic stirrer in $200 \mathrm{~mL}$ of anhydrous toluene containing $4 \mathrm{~g}$ of APTMS and $4 \mathrm{~g}$ of DIEA according to experimental conditions given in Table S1. The suspension was heated at reflux under nitrogen atmosphere for $12 \mathrm{~h}$. The modified silica $\left(\mathrm{ANI} @ \mathrm{SiO}_{2}\right)$ was rinsed with $30 \mathrm{~mL}$ of THF, dried at $60^{\circ} \mathrm{C}$ overnight and stored under vacuum for subsequent uses.

Then ANI@SiO ${ }_{2}$ was copolymerized with aniline. 500 mg of $\mathrm{ANI@SiO}{ }_{2}$ was dispersed in $100 \mathrm{~mL}$ of $\mathrm{HCl}$ aqueous solution at $\mathrm{pH}=4$ in the presence of $186 \mathrm{mg}$ (2 mmol) of aniline monomer and $123 \mathrm{mg}(0.4 \mathrm{mmol})$ of BP4 template molecule. The BP4 to aniline mole ratio was 1:5. The reaction vessel was cooled to $0^{\circ} \mathrm{C}$ in an ice bath and $276 \mathrm{mg}$ of ammonium persulfate (APS) in $2 \mathrm{~mL}$ of water was added dropwise. The reaction was run at $0{ }^{\circ} \mathrm{C}$ for $8 \mathrm{~h}$. The prepared BP4-PANI@MIP was isolated by filtration and washed repeatedly with water till absence of UV-vis absorption in the filtrate. The precipitate was then dried under vacuum at $40{ }^{\circ} \mathrm{C}$ for $24 \mathrm{~h}$. BP4 was extracted from the MIP material first by washing with aqueous ammonia solution $(0.3 \mathrm{M})$ and then with methanol $(\mathrm{MeOH})$ using Soxhlet extraction. Finally, the imprinted polymer (PANI@MIP) was dried under vacuum at $40^{\circ} \mathrm{C}$ for $24 \mathrm{~h}$. The full protocol is summarized in Scheme 1. The non-imprinted polymer (PANI@NIP) was prepared using the same protocol in the absence of BP4; it was also subjected to the same extraction cycles. The $\mathrm{pH}$ was adjusted with hydrochloric acid ( $\mathrm{HCl} 1 \mathrm{M}$ ) and sodium hydroxide ( $\mathrm{NaOH} 1 \mathrm{M}$ ) throughout the whole study. 


\section{Characterization methods}

Infrared absorption spectra were recorded with a Bruker IFS 55 Equinox FTIR spectrometer in ATR mode. Thermogravimetric analyses (TGA) were performed using a TG209F1 Netzsch instrument in the temperature range of $25-1000^{\circ} \mathrm{C}$ at a rate of $10^{\circ} \mathrm{C} \cdot \mathrm{min}^{-1}$ under nitrogen flow. Solid state ${ }^{13} \mathrm{C}$ and ${ }^{29} \mathrm{Si}$ NMR spectra were respectively recorded at $125.768 \mathrm{MHz}$ and 99.362 MHz Larmor frequencies on Bruker Avance III 500 ultra shield Plus. Zeta potentials were measured by electrophoresis with Malvern Zetasizer Nano ZS, with $0.05 \mathrm{wt} \%$ aqueous suspensions at different $\mathrm{pH}$. The $\zeta$ potential was calculated from the electrophoretic mobility under the Smoluchowski approximation. Absorbance spectra of BP4 solutions in $1 \mathrm{~cm}$ optical path quartz cuvettes were recorded using a Perkin-Elmer Lambda 2 UV-vis spectrophotometer. Transmission electron microscopy (TEM) observations were performed at the "Centre Technologique des Microstructures” (CT $\mu$ ) facility of the University of Lyon 1 (http://microscopies.univ-lyon1.fr/) using a Philips CM120 microscope operating at $80 \mathrm{kV}$ acceleration. A drop of $0.1 \%$ aqueous dispersion was deposited on a formvar grid and dried in open air before TEM observation. Chromatographic analyses were carried out on a HPLC system Agilent 1100 equipped with DAD UV-detector and a reverse phase $\mathrm{C}_{8}$ column $(250 \mathrm{~mm} \times 4 \mathrm{~mm}$ i.d., $5 \mathrm{~mm}$ ). Mobile phase was $\mathrm{MeOH}$ : ammonium acetate buffer $\mathrm{pH}$ 6.9. Flow rate was $0.5 \mathrm{~mL} \cdot \mathrm{min}^{-1}$, injection volume was $20 \mu \mathrm{L}$, oven temperature was $30^{\circ} \mathrm{C}$, and $\mathrm{BP} 4$ was detected at $286 \mathrm{~nm}$ wavelength.

\section{Adsorption experiments}

Adsorption measurements were performed by the depletion method. For equilibrium adsorption, 10 mg of PANI@MIP or PANI@NIP were dispersed in 5 mL of 0.07 mM BP4 aqueous solution by magnetic stirring. The initial pH of both BP4 solutions and adsorbents (PANI@MIP and PANI@NIP) was adjusted to 2, 4, 5 or 7 with $\mathrm{HCl} 1 \mathrm{M}$. Continuous mixing was maintained for $12 \mathrm{~h}$ to ensure adsorption equilibrium was reached. Mixtures were centrifuged and the free BP4 concentrations were measured in the supernatant by absorbance analysis at $286 \mathrm{~nm}$. The same method was used for kinetic adsorption measurements. The mixtures were stirred for different contact times $t$, and the concentration in the supernatant was measured after centrifugation. The dynamic adsorption capacities expressed as surface concentrations $\left(\mu \mathrm{mol} \cdot \mathrm{m}^{-2}\right) \Gamma(t)$ or the equilibrium value $\Gamma(\infty)$ were calculated as

$\Gamma(t)=\frac{(C(0)-C(t)) V}{m A_{\mathrm{sp}}}$

Eq SI1

where $C(0)$ and $C(t)$ respectively are the initial and kinetic concentrations of adsorbate, $V$ is the volume of BP4 solution, $m$ is the mass of adsorbent, and $A_{\mathrm{sp}}=140 \mathrm{~m}^{2} \cdot \mathrm{g}^{-1}$ is the specific surface area of adsorbent measured by the BET method. Equilibrium adsorption is given by $\Gamma_{\mathrm{e}}=\Gamma(\infty)$ as a function of $C_{\mathrm{e}}=C(\infty)$, that is, after long enough equilibration time. Experiments were carried out at $298 \mathrm{~K}$ unless specifically stated. 


\section{SI2. Grafting APTMS to silica surface}

Two processes were investigated for grafting of $\mathrm{N}$-[3-(trimethoxysilyl)propyl]aniline silane (APTMS) as a dense monolayer at the surface of silica.

The anhydrous process involves a direct reaction of surface silanols of silica with the methoxy groups of APTMS according to the reaction:

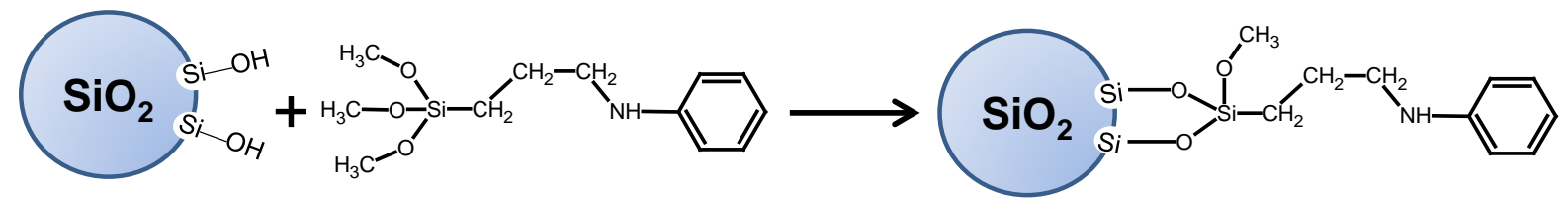

The wet process is performed in a methanol/water mixed solvent. It involves hydrolysis of methoxysilyl groups of APTMS into silanol reactive groups that subsequently condense to silica surface as $\mathrm{Si-O-Si} \mathrm{linkages:}$

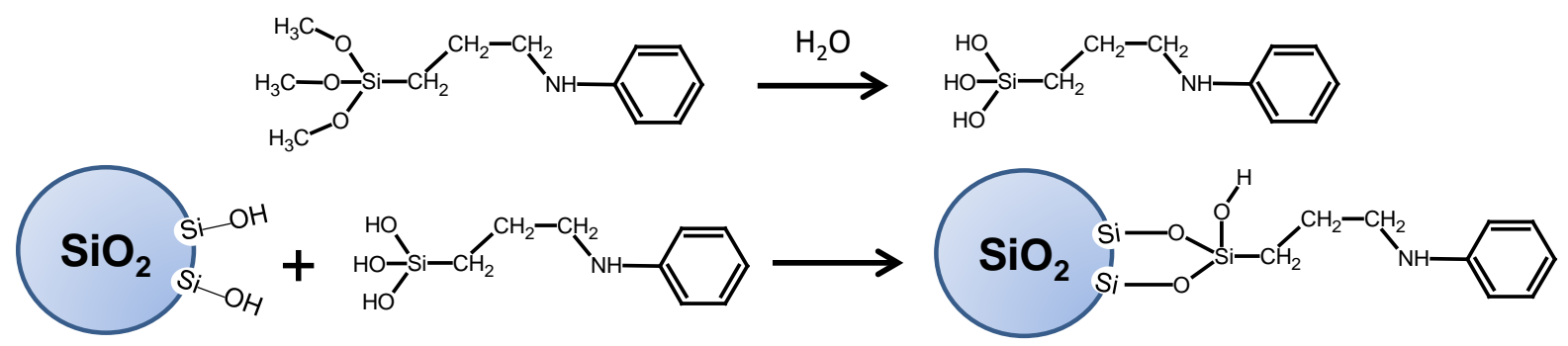

In both processes, addition of diisopropylethylamine catalyst (DIEA) was checked. $5 \mathrm{~g}$ of dried silica was dispersed with a magnetic stirrer in $200 \mathrm{~mL}$ of solvent containing $4 \mathrm{~g}$ of APTMS and $4 \mathrm{~g}$ of DIEA according to experimental conditions given in Table S1. The suspension was heated at reflux under nitrogen atmosphere for $12 \mathrm{~h}$. The modified silica (ANI@SiO ${ }_{2}$ ) was rinsed with $30 \mathrm{~mL}$ of THF and dried at $60^{\circ} \mathrm{C}$ overnight. The grafting densities (Table S1) were estimated from elemental analyses of carbon and nitrogen and from thermogravimetric analyses (TGA). The grafting density was calculated from elemental analyses of carbon $(\% \mathrm{C})$ and nitrogen $(\% \mathrm{~N})$, the chemical formula of the grafts $\left(\mathrm{SiC}_{9} \mathrm{H}_{12} \mathrm{~N}\right)$ and the specific area $A_{\mathrm{sp}}=200 \mathrm{~m}^{2} \cdot \mathrm{g}^{-1}$ measured by the BET method:

Surface density $\left(\mathrm{mol} \cdot \mathrm{m}^{-2}\right)=\frac{\% \mathrm{C}}{100 \times 9 \times 12 \times A_{\mathrm{sp}}}$

Eq S2

Surface density $\left(\mathrm{mol} \cdot \mathrm{m}^{-2}\right)=\frac{\% \mathrm{~N}}{100 \times 14 \times A_{\mathrm{sp}}}$

Eq S3

It was also calculated from the mass loss measured by TGA (Figure S1). A slight mass loss was observed from 100 to $200{ }^{\circ} \mathrm{C}$ corresponding to evaporation of moisture. This mass loss can be large in case of moisturized sample (ANI3@SiO ${ }_{2}$ in Figure S1). The main mass loss occurred between 350 and $600{ }^{\circ} \mathrm{C}$ with an inflexion point at $450{ }^{\circ} \mathrm{C}$; it was ascribed to the thermal decomposition of the organic grafts. Bare silica was also loosing mass in the whole temperature range because of moisture evaporation and dehydroxylation of $\mathrm{Si}-\mathrm{OH}$ groups at the surface of silica. ${ }^{[1]}$ The mass loss due to this later effect was not the same for bare and grafted silica because 
the surface density of $\mathrm{Si}-\mathrm{OH}$ groups was less in grafted silica. Such mass loss was estimated as the distance between tangents to the low and high temperature branches. Considering that thermal cleavage took place at the Si-C bond, the molar mass of the lost moiety $-\left(\mathrm{CH}_{2}\right)_{3}-\mathrm{NH}-\mathrm{C}_{6} \mathrm{H}_{5}$ was $134 \mathrm{~g} \cdot \mathrm{mol}^{-1}$, and the grafting density was calculated as

Surface density $\left(\mathrm{mol} \cdot \mathrm{m}^{-2}\right)=\frac{\% \text { mass loss }}{100 \times 134 \times A_{\mathrm{sp}}}$

Grafting densities inferred from elemental analyses of carbon and nitrogen and from TGA mass loss were in close accordance, giving confidence with the underlying hypotheses of calculations and showing that the chemical structure of grafts used in calculations was correct. The surface density of grafts for ANI1@SiO ${ }_{2}$ was rather high $\left(2.24 \mu \mathrm{mol} \cdot \mathrm{m}^{-2}\right.$ calculated from 6.0\% mass loss in TGA) but it remained lower than the theoretical density of a dense monolayer of close-packed molecules (an estimate is $3-4 \mu \mathrm{mol} \cdot \mathrm{m}^{-2}$ ) ${ }^{[2]}$, so that that the risk for the formation of a thick layer of polysiloxane by polycondensation of the organosilane was kept low. There is no definite proof for the sole formation of a monolayer however, as polycondensation of APTMS could form short strands of poly(3-propylaniline siloxane) bound to the silica surface. The chemistry of grafting aminated organosilane is complex as it is well illustrated by the huge literature on (3aminopropyl)triethoxysilane. ${ }^{[3]}$ Entering the details is out of the scope of the present paper. This material was selected for the manufacture of MIP's because it was a rather dense layer and it had the lowest grafted density among the series (Table S1) that can most likely be as a monolayer.

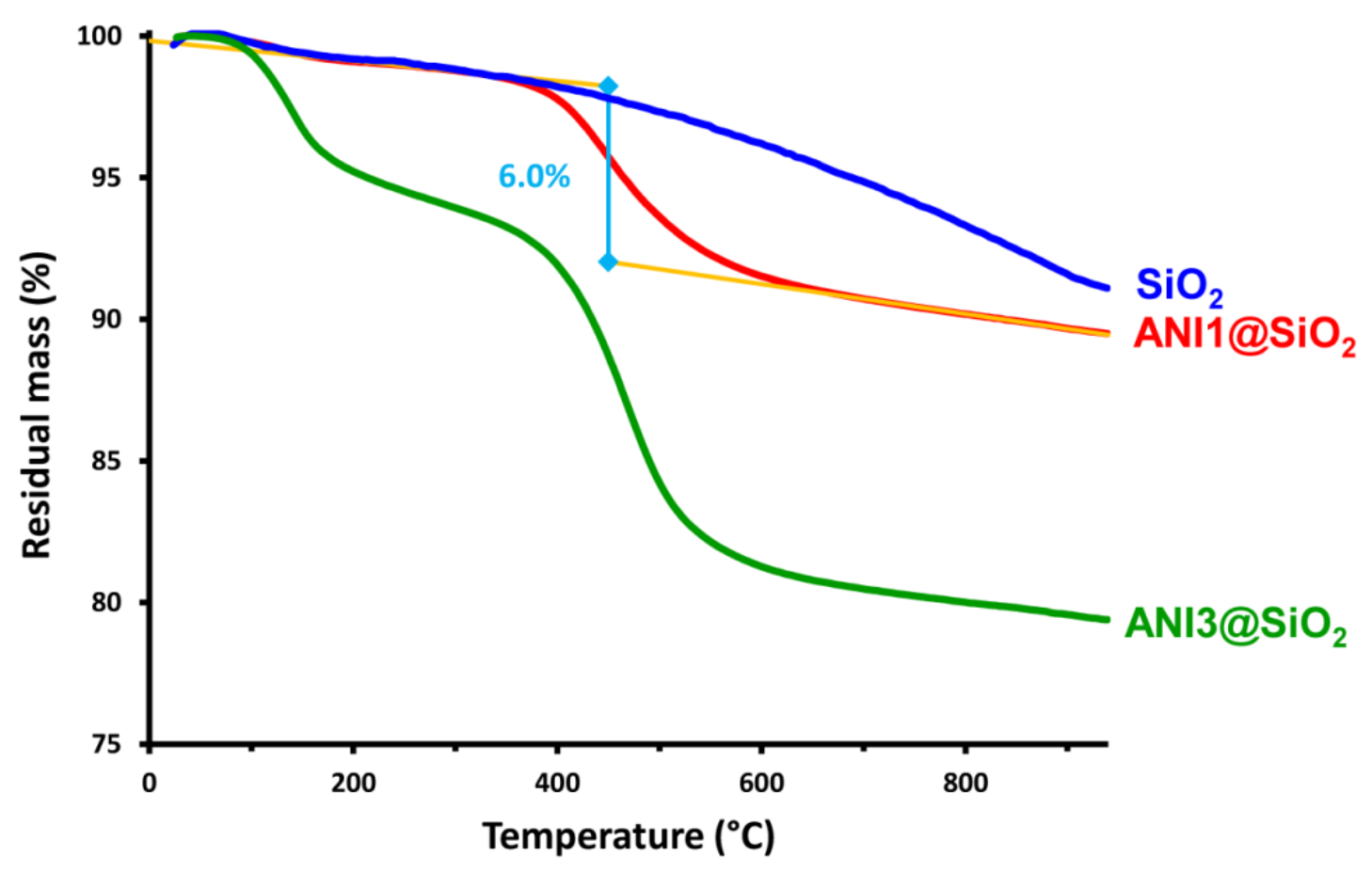

Figure S1.TGA of ANI1@SiO, ANI3@SiO 2 and bare $\mathrm{SiO}_{2}$. 
Table S1. APTMS grafting conditions and surface densities of aniline-modified silica determined from elemental analyses and mass losses between 350 and $600{ }^{\circ} \mathrm{C}$ in TGA.

\begin{tabular}{|c|c|c|c|c|c|c|c|c|}
\hline \multirow{3}{*}{ Material } & \multirow{3}{*}{ Solvent } & \multicolumn{2}{|c|}{ Reagent (g L ${ }^{-1}$ ) } & \multirow{2}{*}{\multicolumn{2}{|c|}{$\begin{array}{c}\text { Elemental } \\
\text { analysis (\%) }\end{array}$}} & \multicolumn{3}{|c|}{ Surface density $\left(\mu \mathrm{mol} \cdot \mathrm{m}^{-2}\right)$} \\
\hline & & \multirow[t]{2}{*}{ Silane } & \multirow[t]{2}{*}{ DIEA } & & & \multicolumn{2}{|c|}{$\begin{array}{c}\text { from elemental } \\
\text { analysis }\end{array}$} & \multirow{2}{*}{$\begin{array}{l}\text { from } \\
\text { TGA }\end{array}$} \\
\hline & & & & C & $\mathbf{N}$ & C & $\mathbf{N}$ & \\
\hline${\mathrm{ANI1} @ \mathrm{SiO}_{2}}$ & $\begin{array}{l}\text { Anhydrous } \\
\text { toluene }\end{array}$ & 20 & 20 & 5.16 & 0.58 & 2.4 & 2.1 & 2.24 \\
\hline $\mathrm{ANI} @ \mathrm{SiO}_{2}$ & $\begin{array}{l}\text { Anhydrous } \\
\text { toluene }\end{array}$ & 20 & - & 6.05 & 0.7 & 2.8 & 2.5 & 2.6 \\
\hline $\mathrm{ANI3@SiO}_{2}$ & $\begin{array}{c}\mathrm{MeOH} / \mathrm{H}_{2} \mathrm{O} \\
(95 / 5, \mathrm{v} / \mathrm{v})\end{array}$ & 20 & 20 & 9.3 & 1.1 & 4.3 & 3.9 & 4.1 \\
\hline $\mathrm{ANI} @ \mathrm{SiO}_{2}$ & $\begin{array}{c}\mathrm{MeOH} / \mathrm{H}_{2} \mathrm{O} \\
(95 / 5, \mathrm{v} / \mathrm{v})\end{array}$ & 20 & - & 5.83 & 0.68 & 2.7 & 2.4 & 2.6 \\
\hline
\end{tabular}

The IR spectrum of ANI1@SiO 2 (Figure S2) showed a very strong absorption band at $1200 \mathrm{~cm}^{-1}$ corresponding to the Si-O-Si vibrations of bulk silica and supplementary bands (highlighted by red circles) corresponding to the grafts: symmetric and asymmetric stretching vibrations of $\mathrm{C}-\mathrm{H}$ bonds at 2930 and $2870 \mathrm{~cm}^{-1}$ and $\mathrm{C}=\mathrm{C}$ stretching of aniline aromatic ring at 1606 and $1509 \mathrm{~cm}^{-1}$. IR spectroscopy provided a qualitative confirmation of successful APTMS grafting. ${ }^{[4]}$

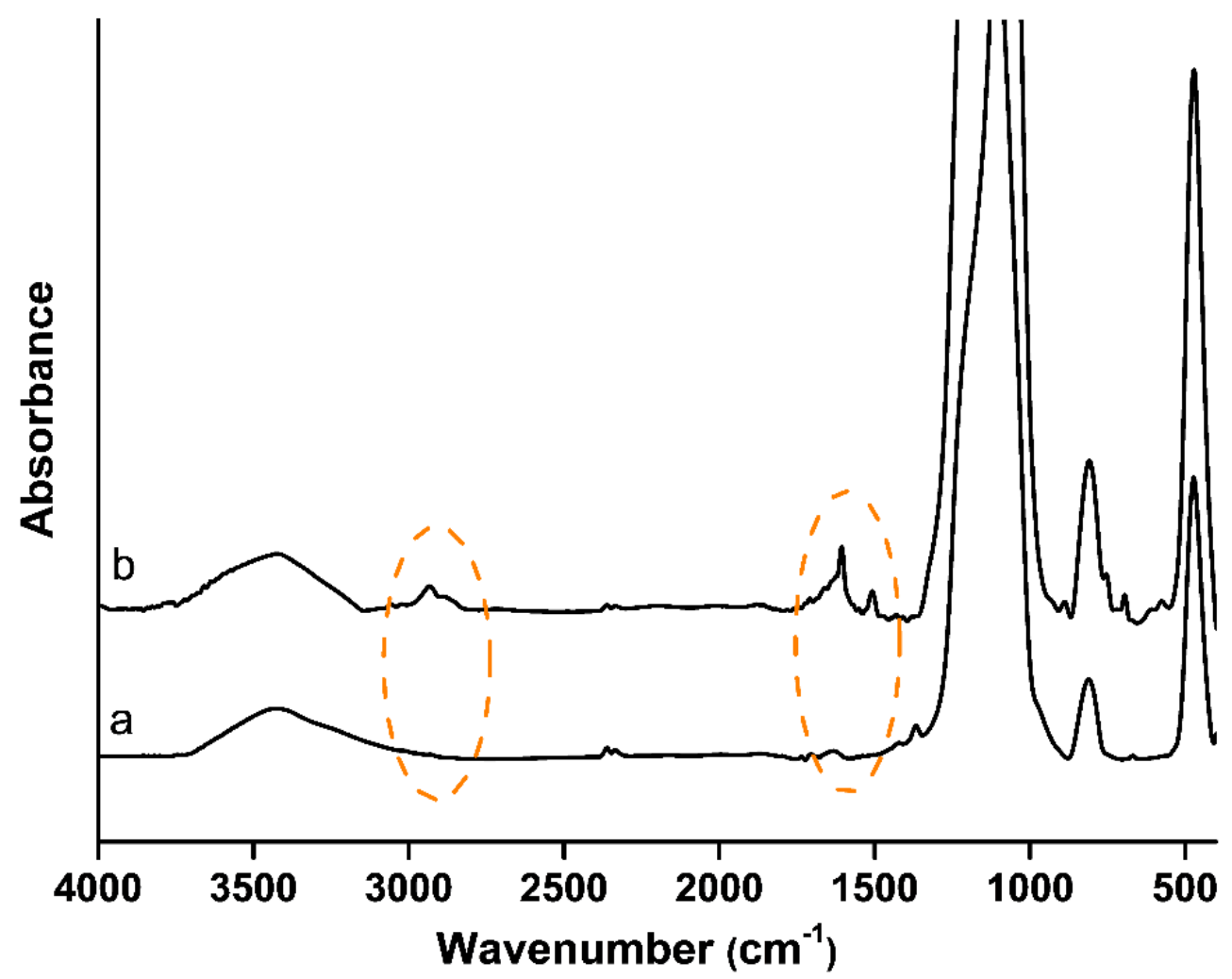

Figure S2. IR spectra of non-modified $\mathrm{SiO}_{2}$ (a) and $\mathrm{ANI} 1 @ \mathrm{SiO}_{2}$ (b). 
CP-MAS ${ }^{13} \mathrm{C}$ NMR spectrum also gave such confirmation as all expected peaks of the $\mathrm{N}$ propylaniline moiety were present (Figure S3). Evidence of residual methoxysilyl groups is also given by the ${ }^{13} \mathrm{C}$ NMR spectrum. This is indeed often the case with trialkoxysilanes, ${ }^{[3,5]}$ especially when grafting takes place in a dry organic solvent. ${ }^{[6]}$ The presence of such residual methoxysilyl groups shows that only part of them (two out of three) actually reacted with surface silanol groups. This is indeed difficult to bind the silicon atom of the silane to a solid surface through three $\mathrm{Si}-\mathrm{O}-\mathrm{Si}$ chemical bonds because it would force changing a lot $\mathrm{O}-\mathrm{Si}-\mathrm{O}$ bond angles around the silicon atom of the silane, thus straining too much chemical bonds.

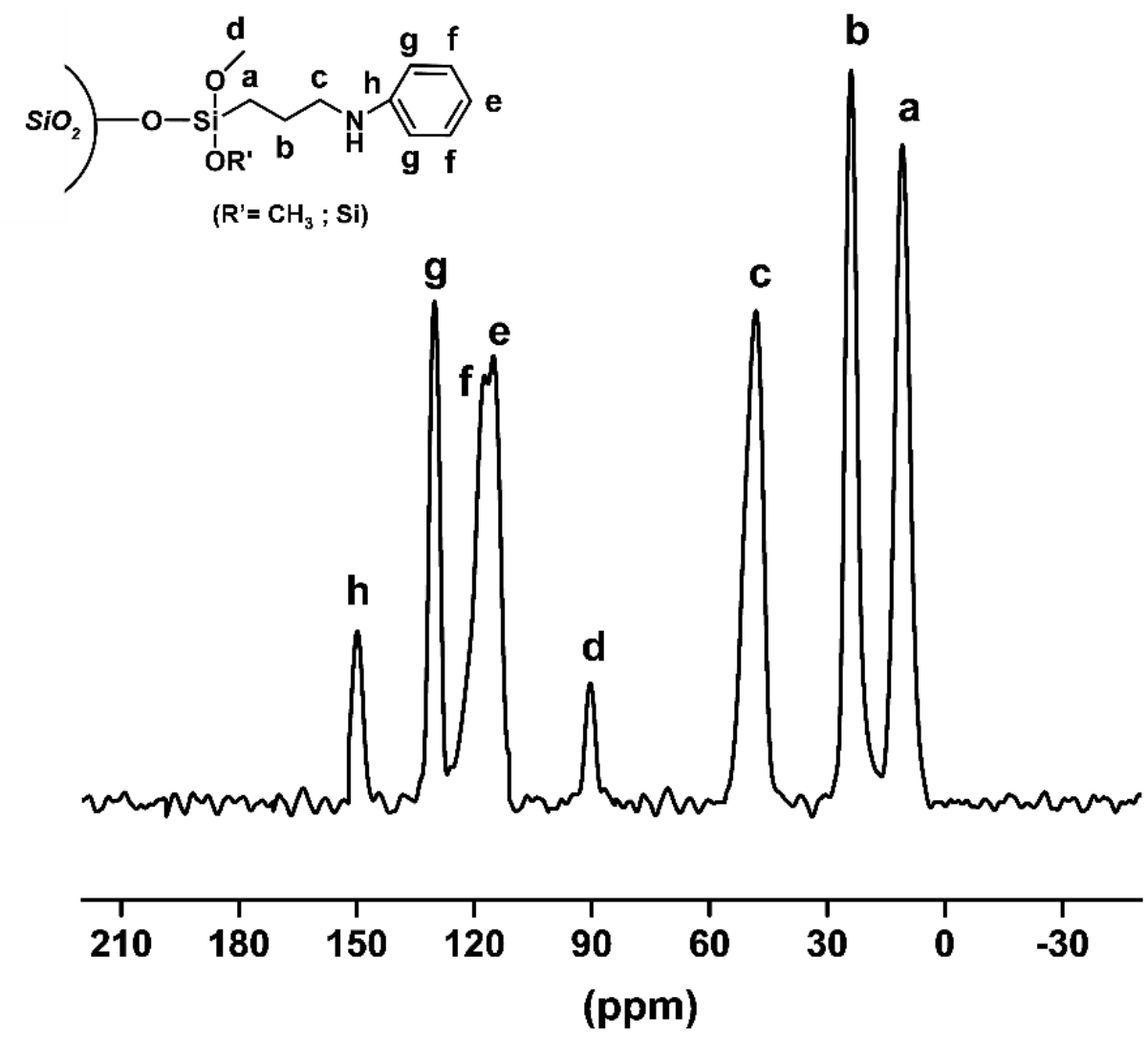

Figure S3. ${ }^{13} \mathrm{C}$ NMR spectrum of organic moiety grafted to modified silica ANI1@SiO 2 .

Supplementary confirmation of grafting came from the observation of the Si-O-Si bonds formed upon grafting by CP-MAS ${ }^{29} \mathrm{Si}$ NMR (Figure S4). The spectrum showed the $\mathrm{Q}^{4}$ and $\mathrm{Q}^{3}$ lines of bulk silica and surface silanols respectively, together with the peaks of the silicon nucleus of grafts bound to silica by one, two and three chemical bonds, denoted $\mathrm{T}^{1}, \mathrm{~T}^{2}$ and $\mathrm{T}^{3}$ respectively. ${ }^{[7]}$ 


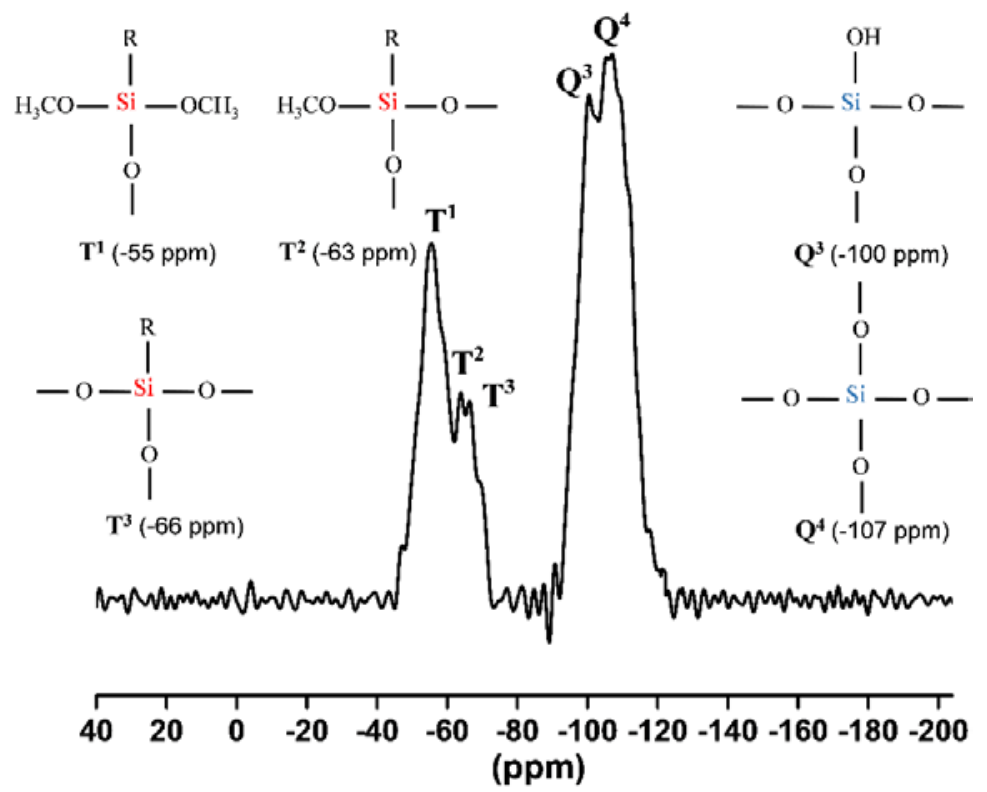

Figure S4. ${ }^{29} \mathrm{Si}$ NMR spectrum of modified silica ANI1@SiO 2.

TEM pictures of ANI1@SiO 2 at low magnification (Figure S5a) showed the silica nanoparticles strongly aggregated together as a porous material. Higher magnification (Figure S5b) revealed the spherical shape of primary silica nanoparticles and their smooth surface.
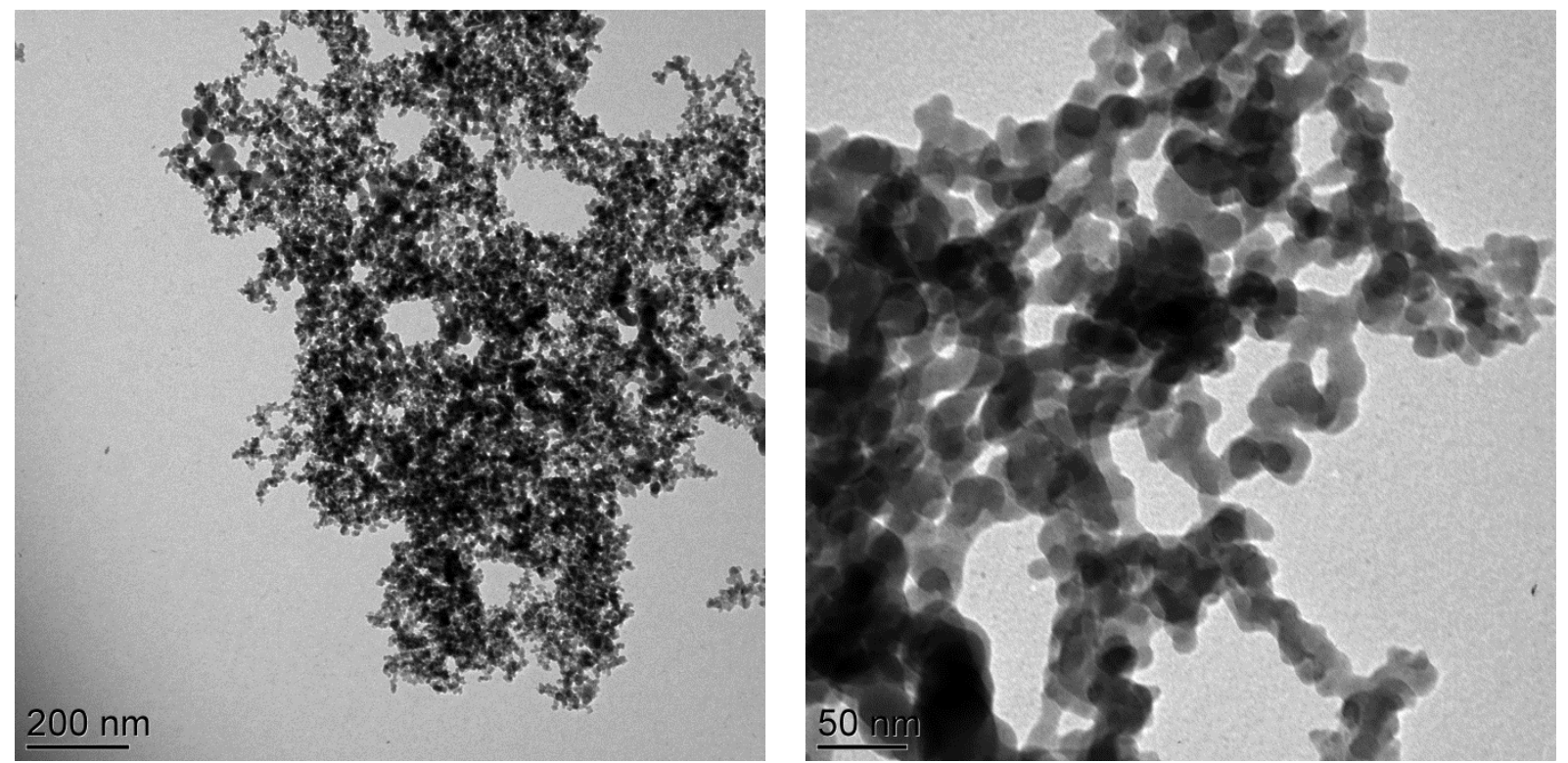

Figure S5. TEM images of monodisperse nanoparticles of ANI1@SiO ${ }_{2}$. 


\section{SI3. Determination of chemical composition of MIP and NIP grafted layers from TGA}

TGA of PANI@MIP (Figure 4 of the main text) shows a single broad step with inflexion point at $750{ }^{\circ} \mathrm{C}$, corresponding thermal decomposition of the full organic materials bound to the silica surface. The onset of PANI degradation was at $290{ }^{\circ} \mathrm{C}$. Dehydroxylation of the $\mathrm{SiO}_{2}$ surface takes place over the full temperature range and the mass loss is quasi-linear. ${ }^{[1]}$ The linear mass loss in the low-temperature range was estimated by extrapolation of the mass losses below $290^{\circ} \mathrm{C}$. The mass loss due to dehydroxylation in the high temperature range could be taken by extrapolation of data above $800{ }^{\circ} \mathrm{C}$ for BP4-PANI@MIP. Thermal decomposition of PANI@MIP extended up to $950^{\circ} \mathrm{C}$. Indeed, PANI@MIP was under its emeraldine base form after extraction of BP4 by ammonium hydroxide solution whereas BP4-PANI@MIP was under its emeraldine salt form. The emeraldine base is thermally more stable than the emeraldine salt. The temperature range of the TGA record from $950^{\circ} \mathrm{C}$ to the end at $1000^{\circ} \mathrm{C}$ (because of the design of TGA instrument) was too narrow for extrapolation be reliable in case of PANI@MIP, so that the slope of linear mass loss of PANI@MIP was taken equal to that measured for BP4-PANI@MIP. The mass loss coming from PANI was taken as the distance between the two linear mass losses at low and high temperatures (yellow lines in Figure 4). The surface density of aniline was calculated from the mass loss of $18 \%$ from which the mass loss coming from the trimethylene linker $\left(42 \mathrm{~g} \cdot \mathrm{mol}^{-1}\right)$ between the silicon atom and the first aniline group was subtracted. This later mass loss and the surface density of aniline read

Linker mass loss $=$ Mass loss of silane-grafted silica $\times \frac{42}{134}=1.9 \% \quad$ Eq S5

Aniline surface density $\left(\mathrm{mol} \cdot \mathrm{m}^{-2}\right)=\frac{\text { Mass loss }- \text { Linker mass loss }}{100 \times 90.63 \times A_{\mathrm{sp}}} \quad$ Eq S6

where $90.63 \mathrm{~g} \cdot \mathrm{mol}^{-1}$ stands for the molar mass of the aniline fragment in PANI. The surface density of aniline was $8.9 \mu \mathrm{mol} \cdot \mathrm{m}^{-2}$, which corresponded to a mean aniline polymerization degree of 4.

TGA of BP4-PANI@MIP combines mass losses from decomposition of PANI and BP4. These two thermal degradations occur in the same temperature range as shown in TGA records of pure BP4 and emeraldine salt doped with $\mathrm{HCl}$ (Figure S6). 


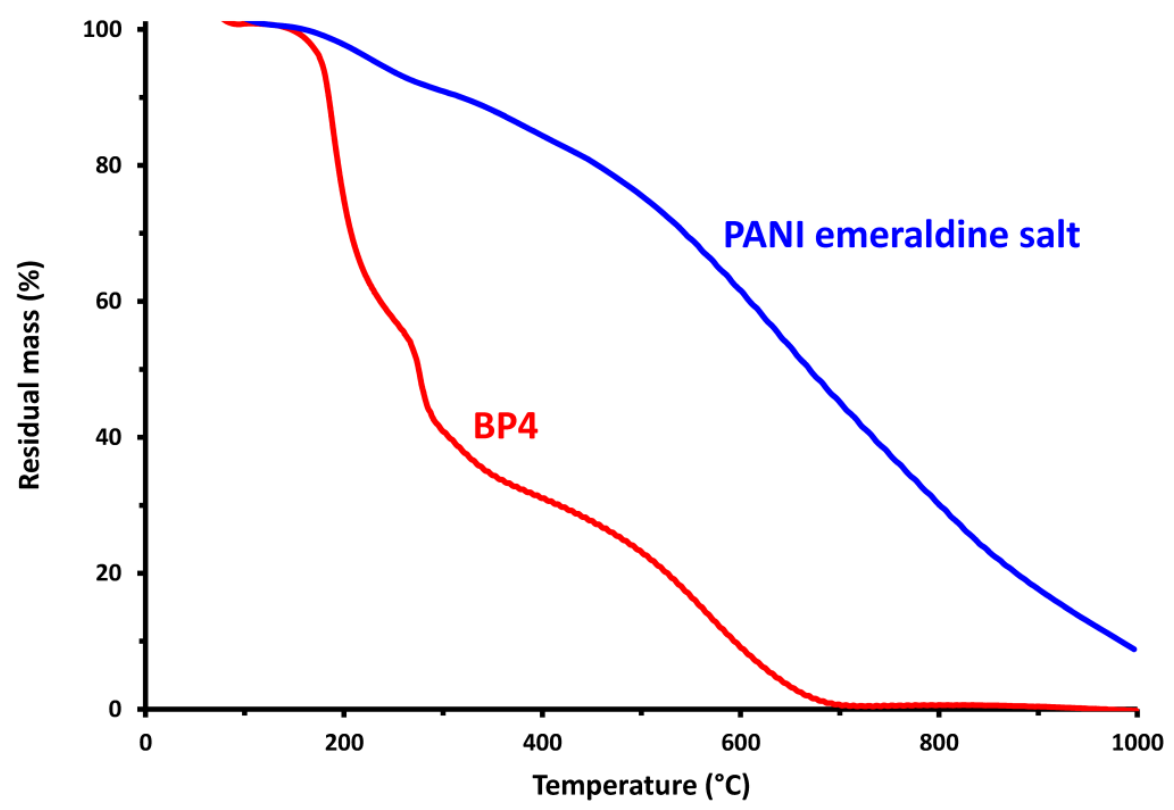

Figure S6. TGA of BP4 and PANI under emeraldine salt form.

Because of the competition between hydrochloric acid and BP4 sulfonic acid for binding to emeraldine salt, both BP4 and chloride anions are present inside the PANI layer. The full mass loss of BP4-PANI@MIP is the sum of mass losses coming from PANI and the two BP4 and $\mathrm{HCl}$ dopants. It is given in terms of surface densities $(S D)$ of the components as

$\%$ mass loss $=100 \times A_{\mathrm{sp}} \times[90.63 \times S D($ Aniline $)+308.31 \times S D(B P 4)+36.5 \times S D(\mathrm{HCl})] \quad$ Eq S7

where the molar masses $90.63,308.31$ and $36.5 \mathrm{~g} \cdot \mathrm{mol}^{-1}$ are those of aniline fragment in PANI, $\mathrm{BP} 4$ and $\mathrm{HCl}$ respectively. Electroneutrality of the PANI emeraldine salt layer having mixed $\mathrm{BP} 4{ }^{-} / \mathrm{Cl}^{-}$counter-anions requires

$S D($ Aniline $)=2 \times\left[S D\left(\mathrm{BP}^{-}\right)+S D\left(\mathrm{Cl}^{-}\right)\right]$

Eq S8

The surface density of aniline was taken the same as for PANI@MIP. Eqs S6 and S7 were solved for the two surface densities $S D\left(\mathrm{BP}^{-}\right)$and $S D\left(\mathrm{Cl}^{-}\right)$. Full results are collected in Table 1 of the main text.

\section{SI4. Interpretation of equilibrium adsorption isotherms in terms of Scatchard plots}

Scatchard plots were used to check whether the surface of both NIP and MIP bore homogeneous or heterogeneous binding sites (Figure S7). Scatchard plot is a linearized expression of the Langmuir adsorption isotherm. In case of homogeneous binding sites, the Scatchard plot of the experimental adsorption isotherm writes as ${ }^{[8]}$

$\frac{\Gamma}{C}=-K \Gamma+K \Gamma_{\max }$

Eq S9 
So, the plot of $\Gamma / C$ against $\Gamma$ is linear and its negative slope gives the binding equilibrium constant $K$. In case of several types of binding sites with very different binding constants, the Scatchard plot shows several parts with linear behavior. The Scatchard plot for NIP was nicely linear over the whole $\Gamma$ range, which indicated adsorption to only one type of binding site. In contrast, the Scatchard plot for the MIP included two distinct linear parts, revealing binding to two kinds of non-equivalent binding sites with different affinities. The binding constant of the NIP calculated from the slope was $K=18350(\log K=4.26)$, provided BP4 concentrations are expressed in $\mathrm{mol} \cdot \mathrm{L}^{-1}$. The surface concentration of adsorbed BP4 is $\Gamma_{\max }=0.21 \mu \mathrm{mol} \cdot \mathrm{m}^{-2}$. Data points for the MIP are too much scattered for the slopes in Scatchard plots allow accurate calculations of binding constants. Scatchard plots just gave evidence of the presence of one type of binding site in the NIP and two types of binding sites in the MIP.
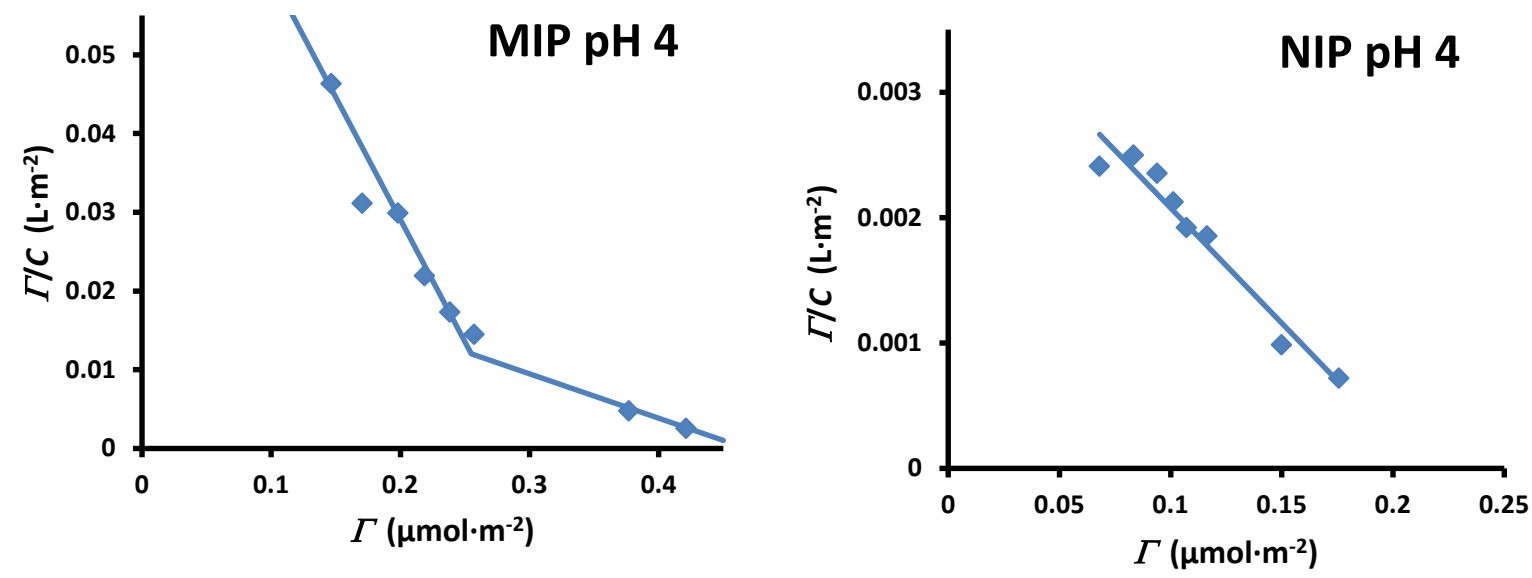

Figure S7. Scatchard plots for binding data of BP4 to PANI@MIP and PANI@NIP at pH 4.

\section{SI5. Interpretation of equilibrium adsorption using Langmuir isotherms}

The Langmuir adsorption isotherm was fitted to the experimental data because this is the most commonly used type of adsorption isotherm. Although the Langmuir theory describes localized adsorption processes on surface sites and should not be used in case of adsorption as a layer of mobile molecules (non-localized adsorption), it is so widely used in the literature that people may wait for its utilization in the present case. The wide use of this model makes it a kind of reference theoretical isotherm. Adsorption on molecular imprints is indeed localized; non-specific adsorption obviously does not and utilization of the Langmuir isotherm is not correct. The Volmer adsorption isotherm was used for non-specific adsorption as a mobile layer in the main part of the present paper. The present section deals with modeling the adsorption data using Langmuir theory for the sake of possible comparison with previous papers of the literature where authors did the same.

The Langmuir adsorption isotherm for non-specific adsorption to NIPs assumes it classical form $^{[9]}$ 
$\Gamma=\Gamma_{\max } \frac{K_{\mathrm{ns}} C}{1+K_{\mathrm{ns}} C}$

Eq S10

where $K_{\mathrm{ns}}$ is the equilibrium constant for non-specific adsorption considered as a quasi-chemical equilibrated reaction of adsorbing molecules and surface sites.

Adsorption onto MIPs takes place on specific molecular imprints and on the non-specific remainder "sites" of the surface. A bi-Langmuir adsorption isotherm is written as the sum of two Langmuir isotherms for the two types of surface sites

$\Gamma=\Gamma_{\max , \mathrm{s}} \frac{K_{\mathrm{s}} C}{1+K_{\mathrm{s}} C}+\Gamma_{\max , \mathrm{ns}} \frac{K_{\mathrm{ns}} C}{1+K_{\mathrm{ns}} C}$

Eq S11

where $K_{\mathrm{s}}$ and $K_{\mathrm{ns}}$ stand for equilibrium constants pertaining to specific and non-specific adsorption equilibria.

The mono-Langmuir and bi-Langmuir theoretical isotherms where fitted to experimental data by minimizing the root-mean-square deviation ( $r m s$ ) by non-linear regression

$r m s=\sqrt{\frac{1}{(N-p)} \sum_{i=1}^{N}\left(\Gamma_{\mathrm{exp}, i}-\Gamma_{\mathrm{calc}, i}\right)^{2}}$

Eq S12

where $N$ and $p$ stand respectively for the number of data points and the number of adjusted variables. The fits of mono-Langmuir and bi-Langmuir isotherms to respectively the NIP and MIP experimental data were quite satisfactory (Figure S8), yielding the $K_{\mathrm{ns}}, K_{\mathrm{s}}, \Gamma_{\max \text {,ns }}$ and $\Gamma_{\max , \mathrm{s}}$ parameters for adsorption isotherms at each $\mathrm{pH}$ (Table S2). The discussion of the parameters in terms of their physicochemical meaning is essentially the same as that given in the main text using the correct Volmer isotherm for the mobile non-selective adsorption and the Langmuir isotherm for localized adsorption on molecular imprints.

Table S2. Parameters of the best fits of the Langmuir and bi-Langmuir models to experimental adsorption isotherms of PANI@NIP and PANI@MIP respectively.

\begin{tabular}{|c|c|c|c|c|c|c|}
\hline \multirow[b]{3}{*}{ pH 2} & \multicolumn{2}{|c|}{ PANI@NIP } & \multicolumn{4}{|c|}{ PANI@MIP } \\
\hline & $K_{\mathrm{ns}}$ & $\begin{array}{c}\Gamma_{\text {max,ns }} \\
\left(\mu \mathrm{mol} \cdot \mathrm{m}^{-2}\right)\end{array}$ & $K_{\mathrm{s}}$ & $\begin{array}{c}\Gamma_{\max , \mathbf{s}} \\
\left(\mu \mathrm{mol} \cdot \mathrm{m}^{-2}\right)\end{array}$ & $K_{\mathrm{ns}}$ & $\begin{array}{c}\Gamma_{\text {max,ns }} \\
\left(\mu \mathrm{mol} \cdot \mathrm{m}^{-2}\right)\end{array}$ \\
\hline & 21700 & 0.86 & 184000 & 0.28 & 25200 & 0.65 \\
\hline pH 4 & 18600 & 0.21 & 686400 & 0.18 & 24400 & 0.30 \\
\hline pH 5 & 61000 & 0.19 & 483400 & 0.17 & 60300 & 0.09 \\
\hline pH 7 & 15300 & 0.07 & - & 0.0 & 28700 & 0.10 \\
\hline
\end{tabular}



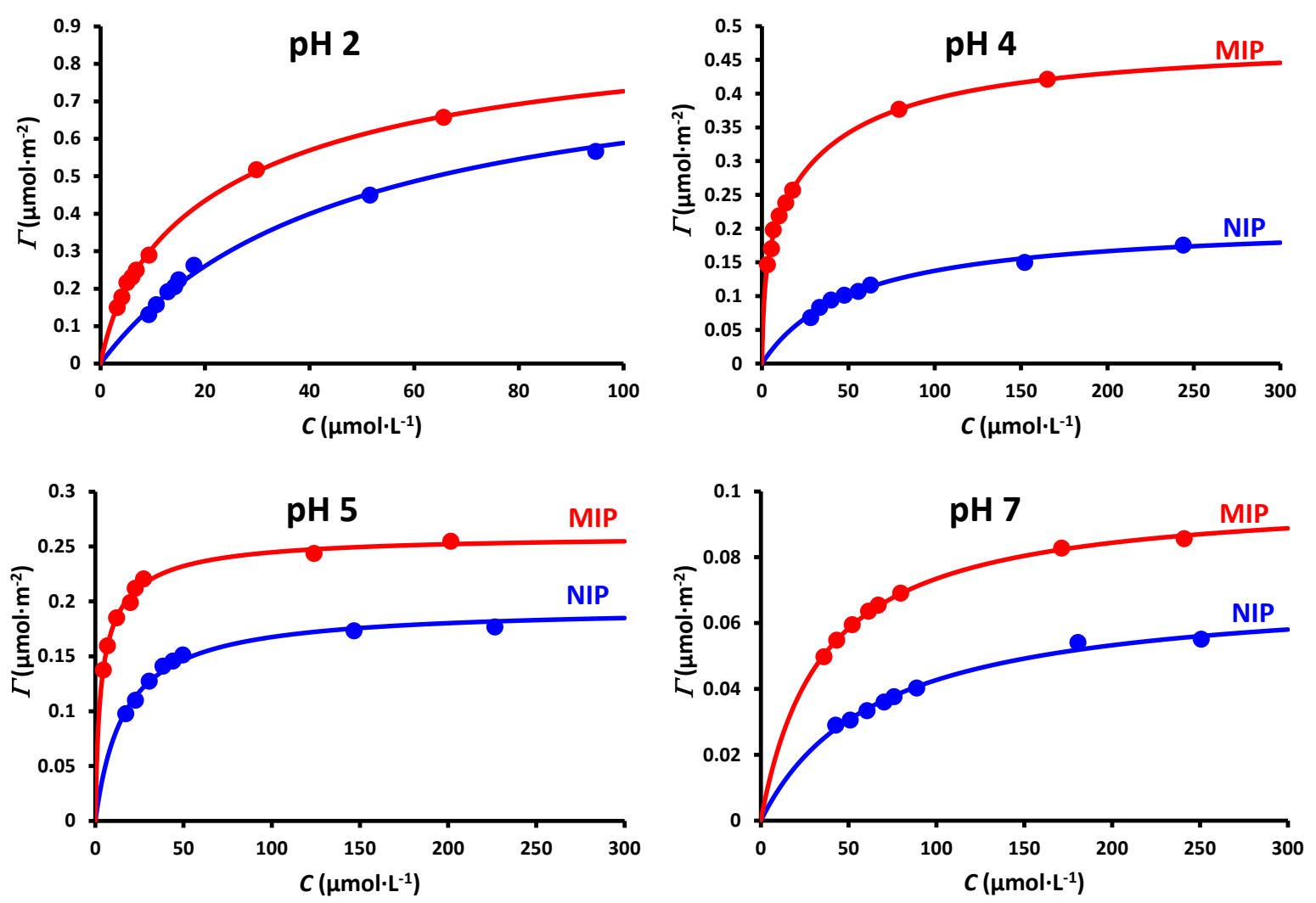

Figure S8. Experimental adsorption isotherms and best fits of the mono-Langmuir and biLangmuir for respectively adsorption of BP4 to PANI@NIP and PANI@MIP at pH 2, pH 4, pH 5 and $\mathrm{pH} 7$.

\section{References}

[1] L. T. Zhuravlev, The surface chemistry of amorphous silica. Zhuravlev model. Colloids Surf. A 2000, 173, 1-38.

[2] J.-F. Erard, L. Nagy, E. sz. Kovats, The preparation of mixed organic layers chemically bonded on silicon dioxide. Colloids Surfaces 1984, 9, 109-132; N. D. Zhuravlev, J. I. Siepmann, M. R. Schure, Surface coverages of bonded-phase ligands on silica: A computational study. Anal. Chem. 2001, 73, 4006-4011.

[3] E. F. Vansant, P. van der Voort, K. C. Vrancken, Characterization and chemical modification of the silica surface. In Studies in Surface Science and Catalysis. Elsevier, Amsterdam, 1995, Chap. 9, pp. 193-265; P. Trens, R. Denoyel, J. Rouquerol, Adsorption of ( $\gamma$-aminopropyl)triethoxysilane on silica from aqueous solution: A microcalorimetric study. Langmuir 1995, 11, 551-554; G. S. Caravajal, D. E. Leyden, G. R. Quinting, G. E. Maciel, Structural characterization of (3-aminopropyl)triethoxysilane-modified silicas by silicon-29 and carbon-13 Nuclear Magnetic Resonance. Anal. Chem. 1988, 60, 17761786; P. Trens, R. Denoyel, Adsorption of ( $\gamma$-aminopropyl)triethoxysilane and related molecules at the silica/heptane interface. Langmuir 1996, 12, 2781-2784; E. T. Vandenberg, L. Bertilsson, B. Liedberg, K. Uvdal, R. Erlandsson, H. Elwing, I. 
Lundström, Structure of 3-aminopropyl triethoxy silane on silicon oxide. J. Colloid Interface Sci. 1991, 147, 103-118; J. H. Moon, J. H. Kim, K.-J. Kim, T.-H. Kang, B.

Kim, C.-H. Kim, J. H. Hahn, J. W. Park, Absolute surface density of the amine group of the aminosilylated thin layers: Ultraviolet-visible spectroscopy, second harmonic generation, and synchrotron-radiation photoelectron spectroscopy study. Langmuir 1997, 13, 4305-4310.

[4] G. Socrates, Infrared Characteristic Group Frequencies. Wiley, New York, 1980, Chap. 10, pp. 51 and 162.

[5] J. P. Blitz, R. S. Shreedhara Murthy, D. E. Leyden, Ammonia-catalyzed silylation reactions of Cab-O-Si1 with methoxymethylsilanes. J. Am. Chem. Soc. 1987, 109, 71417145.

[6] J. W. de Haan, H. M. van den Bogaert, J. J. Ponjeé, L. J. M. van de Ven, Characterization of modified silica powders by Fourier transform infrared spectroscopy and crosspolarization magic angle spinning NMR. J. Colloid Interface Sci. 1986, 110, 591-600.

[7] D. W. Sindorf, G. E. Maciel, Silicon-29 Nuclear Magnetic Resonance study of hydroxyl sites on dehydrated silica gel Surfaces, using silylation as a probe. J. Phys. Chem. 1983, 87, 5516-5521.

[8] G. Scatchard, The attraction of proteins for small molecules and ions. Ann. New York Acad. Sci. 1949, 51 (4), 660-672.

[9] I. Langmuir, The adsorption of gases on plane surfaces of glass, mica and platinum. $J$. Am. Chem. Soc. 1918, 40, 1361-1403. 